\title{
可见光诱导的无过渡金属催化交叉脱氢偶联反应研究进展
}

\author{
孔瑶蕾徐雯秀叶飞霞翁建全* \\ (浙江工业大学化学工程学院 杭州 310014)
}

\begin{abstract}
摘要 交叉脱氢偶联反应通过两种不同的 $\mathrm{X}-\mathrm{H}$ 键直接偶联生成新的化学键, 具有优异的步骤经济性和原子经济性. 传统交叉脱氢偶联反应通常以过渡金属催化，存在催化剂昂贵及污染严重等问题. 可见光诱导电子转移也是实现 X一 $\mathrm{H}$ 键直接官能化的有效途径. 可见光诱导的无过渡金属催化交叉脱氢偶联反应因具有清洁安全、步骤和原子经济性高 等优点从而受到广泛关注. 根据成键类型分类，综述了该类反应的研究进展，并对其前景进行了展望.

关键词 交叉脱氢偶联; 可见光诱导; 无过渡金属; 官能化
\end{abstract}

\section{Recent Advances in Visible-Light-Induced Cross Dehydrogenation Coupling Reaction under Transition Metal-Free Conditions}

\author{
Kong, Yaolei Xu, Wenxiu Ye, Feixia Weng, Jianquan* \\ (College of Chemical Engineering, Zhejiang University of Technology, Hangzhou 310014)
}

\begin{abstract}
The cross dehydrogenation coupling reaction realizes direct coupling of two different $\mathrm{X}-\mathrm{H}$ bonds to form a new chemical bond, thus featuring excellent step and atom economy. The traditional cross dehydrogenation coupling reaction was usually catalyzed by transition metal, which had the problems of expensive catalyst and serious pollution. Visible light-induced electron transfer is also an effective way to realize direct functionalization of $\mathrm{X}-\mathrm{H}$ bonds. Visible-light-induced cross dehydrogenation coupling reaction under transition metal-free conditions is widely concerned due to the advantages of cleanliness, safety as well as high step and atom economy. Classified by the type of bonding, the research progress of these reactions is reviewed, and their future outlook is also discussed.

Keywords cross dehydrogenation coupling; visible-light-induced; transition metal-free; functionalization
\end{abstract}

交叉脱氢偶联反应 $(\mathrm{CDC})$ 直接通过两种不同的 $\mathrm{X}$ $\mathrm{H}$ 键结合生成新的化学键, 过程中避免了反应底物的预 先官能化, 具有优异的步骤经济性和原子经济性, 已成 为化学合成的一种重要的方法 ${ }^{[1 ~ 5]}$. 其中, 雷爱文课题 组在交叉脱氢偶联领域研究广泛, 相继报道了过渡金属 催化 ${ }^{[6]}$ 、自由基介导 ${ }^{[7]}$ 的 $\mathrm{C}-\mathrm{H}$ 官能化反应，随后又从光 化学、热化学和电化学三个角度对代表性反应进行概 述 $^{[8]}$. 传统交叉脱氢偶联反应通常使用铜 ${ }^{[9]}$ 、铁 ${ }^{[10,11]}$ 、 钓 $^{[12]}$ 、钴 ${ }^{[13]}$ 、铱 ${ }^{[14]}$ 、锰 ${ }^{[15]}$ 等过渡金属催化剂, 但是这类 催化剂在催化反应的同时也表现出一系列缺点, 例如价 格昂贵、反应条件严苛、有一定的毒性以及难以避免的 金属残留等, 制约了其在有机合成中的应用 ${ }^{[16 ~ 18]}$. 因 此, 无金属催化的交叉脱氢偶联反应受到人们的关注. 2015 年, Antonchick 课题组 ${ }^{[19]}$ 对无金属催化下不同杂化
类型 $\mathrm{C}-\mathrm{C}$ 键的交叉脱氢偶联反应进行了归纳. 随后, 王涁课题组 ${ }^{[20]}$ 及 Parvatkar 课题组 ${ }^{[21]}$ 也分别以溴试剂和 分子碘为催化剂对相关交叉脱氢偶联反应进行了总结.

近年来，可见光因其储量丰富、廉价易得及清洁安

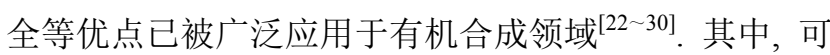
见光诱导电子转移是实现 $\mathrm{X}-\mathrm{H}$ 键直接官能化的有效途 径之一. 可见光诱导的交叉脱氢偶联反应无疑具有步骤 和原子经济性高及反应条件绿色等优点, 因而引起研究 者关注. 2018 年, 吴雨珠课题组 ${ }^{[31]}$ 总结了含钴双催化体 系的光氧化还原交叉脱氢偶联反应. 同年，雷爱文课题 组 ${ }^{[32,33]}$ 综述了 $\mathrm{C}-\mathrm{H} / \mathrm{X}-\mathrm{H}$ 的光诱导交叉脱氢偶联反应 实例. 然而, 对于可见光诱导的无过渡金属催化的交叉 脱氢偶联反应，目前尚无文献对其进行总结和讨论. 鉴 于此，本文根据成键类型的不同，结合近几年来文献报

* Corresponding author. E-mail: jqweng@zjut.edu.cn

Received May 9, 2019; revised June 5, 2019; published online July 9, 2019.

Project supported by the Natural Science Foundation of Zhejiang Province (No. LY17C140003).

浙江省自然科学基金(No. LY17C140003)资助项目. 
道的各种催化体系以及反应底物, 对可见光诱导的无过 渡金属催化交叉脱氢偶联反应及其代表性反应机理进 行了整理和归纳.

\section{$1 \mathrm{C}$ - C 偶联反应}

\section{$1.1 \mathrm{C}\left(\mathrm{sp}^{3}\right)-\mathrm{C}\left(\mathrm{sp}^{3}\right)$ 偶联}

2011 年, Tan 课题组 ${ }^{[34]}$ 报道了可见光诱导叔胺的 $\alpha-$ 官能化反应. 利用孟加拉玫瑰红(Rose Bengal)染料作光 敏剂, 在室温条件下实现了 $N$-芳基四氢异喹啉和硝基 烷烃以及酮的交叉脱氢偶联反应(Eqs. 1, 2). Eq. 2 中, $N$ 芳基四氢异喹啉在吡咯烷/三氟乙酸(TFA)溶液中直接产 生亚胺中间体, 比经典 Mannich 反应操作更简便. 该方 法利用价廉易得的有机染料作为催化剂, 具有反应条件 温和、环境友好的优点.

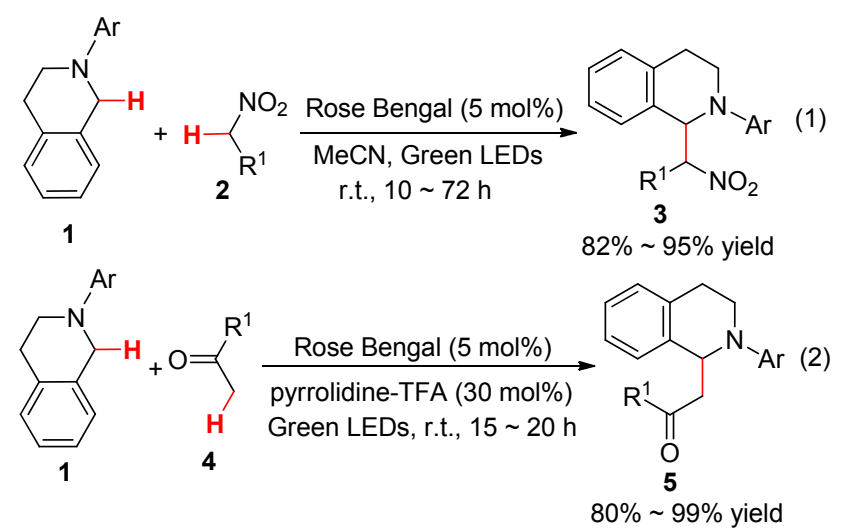

同年, König 等 ${ }^{[35]}$ 以 Eosin Y 染料作光敏剂, 研究了 可见光诱导下 $N$-芳基四氢异喹啉和亲核试剂的 $\mathrm{C}\left(\mathrm{sp}^{3}\right)-\mathrm{H} / \mathrm{C}\left(\mathrm{sp}^{3}\right)-\mathrm{H}$ 偶联反应(Eqs. 3, 4). 与前者相比, 该体系具有催化剂用量低, 反应时间短等优点.<smiles>[R]C([CH]C1c2ccccc2CCN1[Ga])[N+](=O)[O-]</smiles>

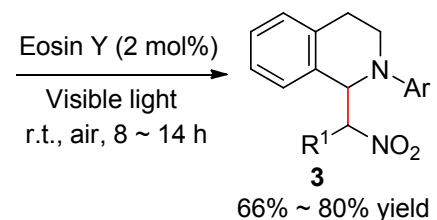<smiles>[R6]OC(=O)C([CH][C@@H]1c2ccccc2CCN1[Al])C([R20])=O</smiles>

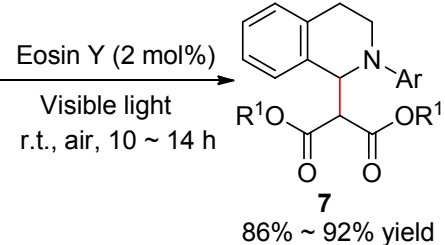

2012 年, 吴骊珠等 ${ }^{[36]}$ 扩展了 $N$-芳基四氢异喹啉衍 生物范围, 将其和硝基烷烃在波长大于 $450 \mathrm{~nm}$ 的光照 下反应, 以曙红 $\mathrm{Y}$ 的四丁基铵盐(TBA-Eosin Y)染料作 光敏剂, 氧气作氧化剂, 得到了一系列交叉脱氢偶联产 物(Eq. 5). 该方法进一步减少了光敏剂用量, 同时也提
高了光催化反应速率.

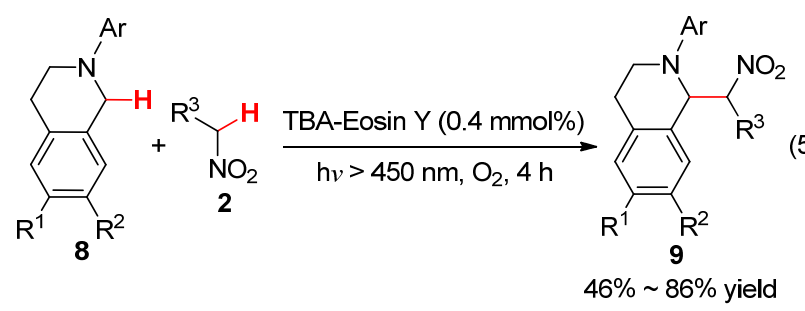

以 $N$-苯基四氢异喹啉(10)和硝基甲烷为例, 推测其 反应机理如下: 首先, TBA-Eosin Y 在光照条件下被激 发生成三线态激发态 TBA-Eosin Y*. 接着, 光诱导电子 从 $N$-苯基四氢异喹啉 (10 转移到 TBA-Eosin $\mathrm{Y}^{*}$ 形成 $N$ 苯基四氢异喹啉自由基正离子(10a)和 TBA-Eosin $\mathrm{Y}^{\circ}$. 随后，电子从 TBA-Eosin $\mathrm{Y}^{-}$转移到氧气和硝基甲烷中, 生成 TBA-Eosin Y, 氢过氧自由基和硝基甲烷自由基负 离子. 同时, 氧气自由基负离子进行质子化, 生成氢过 氧自由基. 其可以与 $N$-苯基四氢异喹啉(10)反应, 夺取 一个氢原子, 进一步形成 $N$-苯基四氢异喹啉自由基 (10b) 和 $\mathrm{H}_{2} \mathrm{O}_{2}$. 另外, 光诱导电子从 $N$-苯基四氢异喹啉 自由基(10b)转移到 TBA-Eosin $\mathrm{Y}^{*}$ 分别产生亚胺离子 10c 和 TBA-Eosin $\mathrm{Y}^{\circ-}$. 最后，硝基甲烷与亚胺离子(10c) 进行亲核加成，从而得到产物 1-硝基- $N$-苯基四氢异喹 啉(11) (Scheme 1).

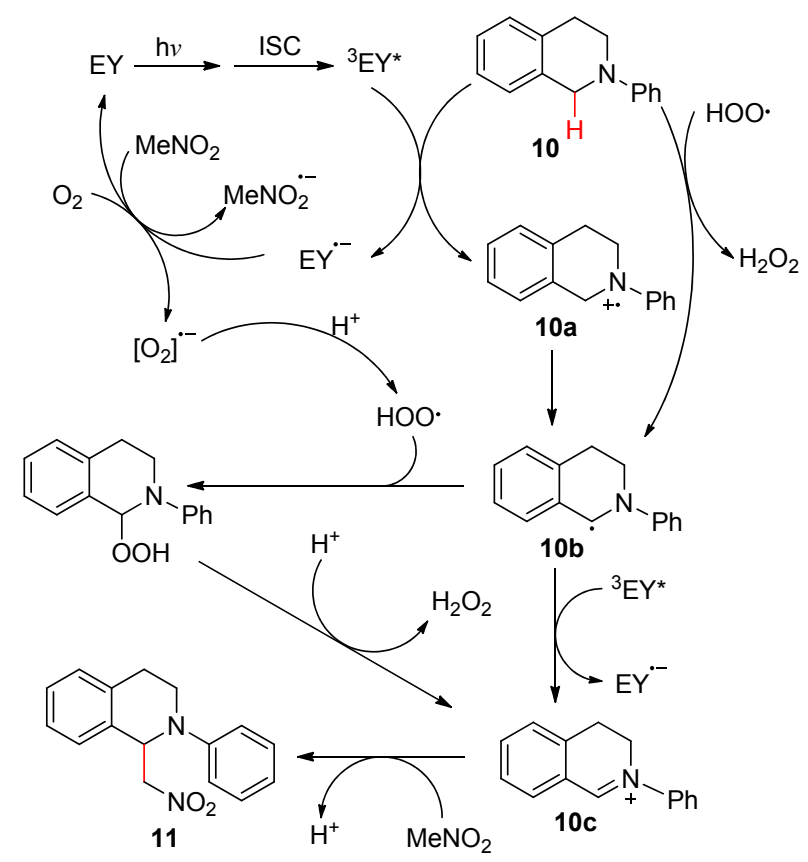

图式 $1 \mathrm{~N}$-苯基四氢异喹啉和硝基甲烷的交叉脱氢偶联反应 机理

Scheme 1 Cross dehydrogenation coupling mechanism of $\mathrm{N}$-phenyltetrahydroisoquinoline and nitromethane

2012 年, Blechert 等 ${ }^{[37]}$ 采用介孔石墨氮化碳(mpg- 
$\mathrm{C}_{3} \mathrm{~N}_{4}$ ) 半导体作为非均相光催化剂, 在可见光的照射下, 氧气作氧化剂合成了 $N$-芳基四氢异喹啉衍生物(Eqs. 6, 7). 此体系可以进一步结合脯氨酸实现氧化串联光催 化. 该方法利用非金属固态有机化合物作为催化剂, 具 有较大的比表面积和丰富的表面积位点, 提高了光捕获 能力和材料的反应吸附能, 又避免了有机染料难以回收 的缺点.
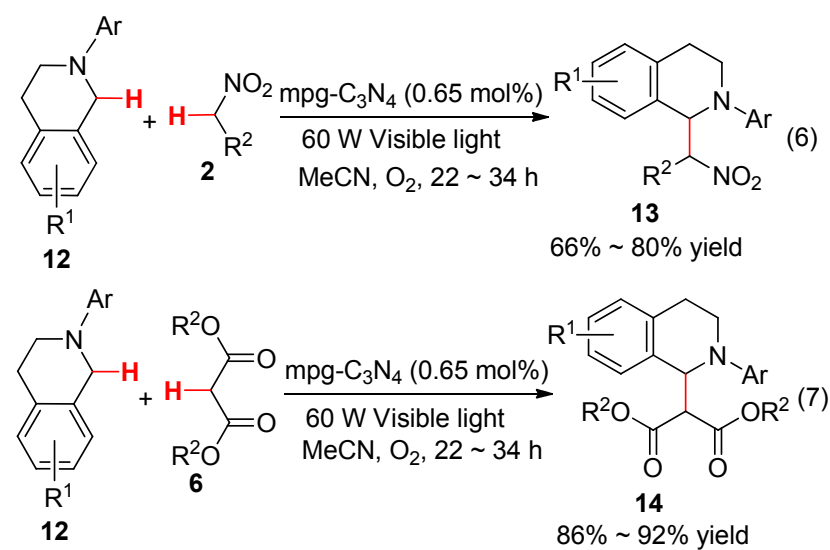

2013 年, Rueping 课题组 ${ }^{[38]}$ 将连续流反应技术应用 到可见光催化氧化叔胺的 $\alpha$-官能化反应中. 在绿光的照 射下, 以孟加拉玫瑰红(Rose Bengal)染料作光敏剂, 乙 腈和水的混合物作溶剂, 在流速为 $0.03 \mathrm{~mL} / \mathrm{min}$ 的连续 反应器中反应 $5 \mathrm{~h}$ 即可得到目标产物(Eqs. 8, 9). 连续流 反应相较于传统的间歇反应, 由于其具有较小的反应通 道和较大的比表面积, 使得反应体系在可见光下受到更 加均匀有效的照射, 从而大大缩短了反应时间, 并且具 有安全、高效的优点.
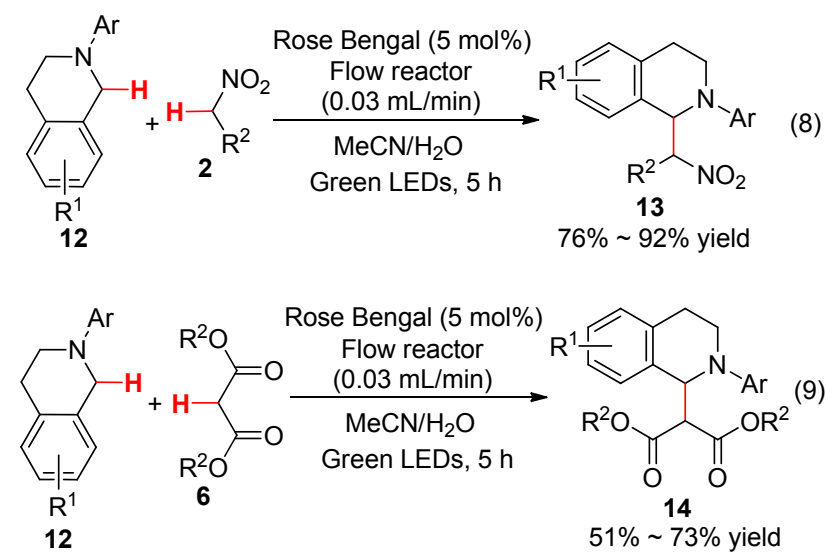

2014 年, 江智勇和 Bureš 等 ${ }^{[39]}$ 报道了以双氧基吡嗪 衍生的发色团(DPZ)作为新型光催化剂的催化氧化反应. 其中, 结构中含有给电子基团 2-甲氧基噻吩的 DPZ 衍 生物表现出强的可见光吸收, 以其作为光催化剂, 在 12 $\mathrm{W}$ 日光灯照射下, 以 $N$-芳基四氢异喹啉、 $N$-(4-叔丁基
苯基)吡咯和二芐胺为底物，与亲核试剂进行交叉脱氢 偶联反应, 获得了良好的产率(Eq. 10). 当以亚磷酸二乙 酯作为亲核试剂时，产率也可达 $81 \%$. 该光催化剂在低 负载量下表现出高催化效率, 它的电化学特性有助于通 过单电子转移产生 $\alpha$-氨基自由基, 更重要的是其平面可 极化的 $\pi$ 系统有助于自由基阴离子的稳定存在, 降低了 能量的消耗, 是一个有望继续发展的绿色催化剂.

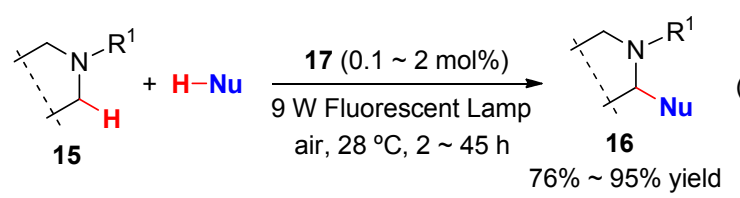<smiles>[R]C(C=NN)[N+](=O)[O-]</smiles>

2014 年, Itoh 课题组 ${ }^{[40]}$ 报道了在光照下, 以 2 -氯萝 醌(2-Cl-AQN)作光催化剂, 氧气作氧化剂, 在甲醇溶剂 中实现了 $N$-芳基四氢异喹啉与亲核试剂硝基烷烃及酮 的交叉偶联反应(Eq. 11). 此反应体系催化剂用量低及 反应条件温和简单, 对吲哚也具有适用性, 但是对于 $N$ 烷基四氢异喹啉催化效果不明显，产物产率低.

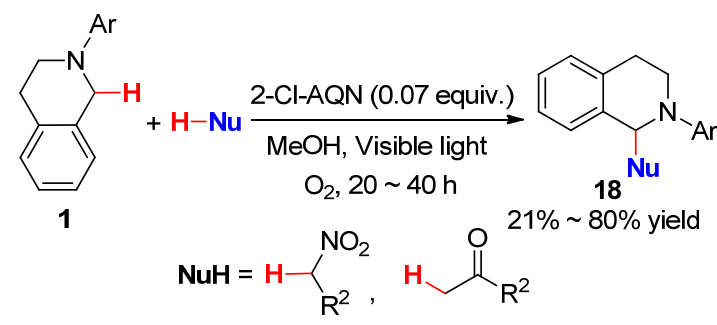

2015 年, 吴骊珠课题组 ${ }^{[41]}$ 报道了氟化硼络合二吡 咯甲川类荧光染料(BODIPY)作为光敏剂的交叉脱氢偶 联反应. 在可见光的照射下, 以 1,3,5,7-四甲基-8-苯基4,4-二氟硼烷基胍(B-1)作光催化剂, 在室温下反应 $3 \sim 6$ $\mathrm{h}$ 即可得到 $N$-芳基四氢异喹啉的衍生物(Eqs. 12,13), 而 且无论富电子还是缺电子亲核试剂, 都获得了高产率的 偶联产物. 与之前三重激发态 ${ }^{3} \mathrm{PS}$ *驱动 $\mathrm{C}-\mathrm{H}$ 键活化的 研究相反, 该课题组首次提出了 BODIPY 单重激发态 ${ }^{1} \mathrm{PS} *$ 促进反应的机理, 为可见光照射下促进有机转化提 供了新方法.

以 $N$-苯基四氢异喹啉(10)和亲核试剂 $\mathrm{NuH}$ 为例，推 测其反应机理如下: PS(B-1)受到光照后转化成单重激发 态 ${ }^{1} \mathrm{PS}^{*}$, 其立即被 $N$-苯基四氢异喹啉(10)还原猝灭, 通 过电子转移产生 $N$-苯基四氢异喹啉自由基正离子(10a) 


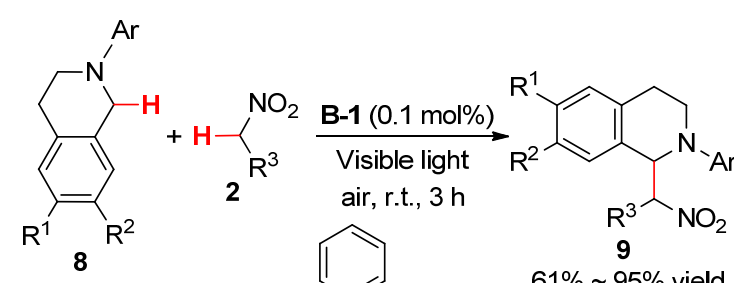

$61 \% \sim 95 \%$ yield<smiles>Cc1cc(C)n2c1-c1c(C)cc(C)n1C(F)(F)[B-]2(F)F</smiles>

B-1

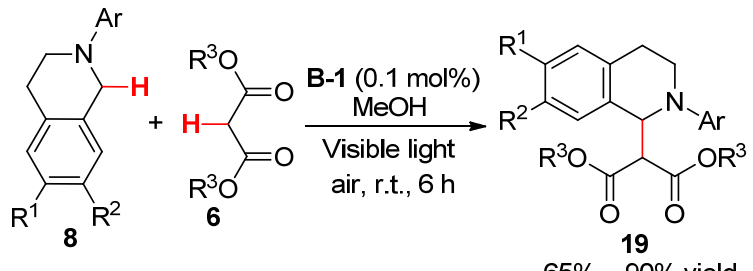

$65 \% \sim 90 \%$ yield

和 $\mathrm{PS}^{--}$, 生成的 $\mathrm{PS}^{--}$将电子转移给氧气以形成氧气自由 基负离子，同时再生基态 PS 用于催化循环. 随后，氧气 从 $10 \mathrm{a}$ 中夺取一个氢原子生成自由基 $10 \mathrm{~b}$ 和氢过氧自由 基, 10b 进一步被氧气氧化生成亚胺 10c, 最后被亲核试 剂进攻生成目标产物 20 (Scheme 2).

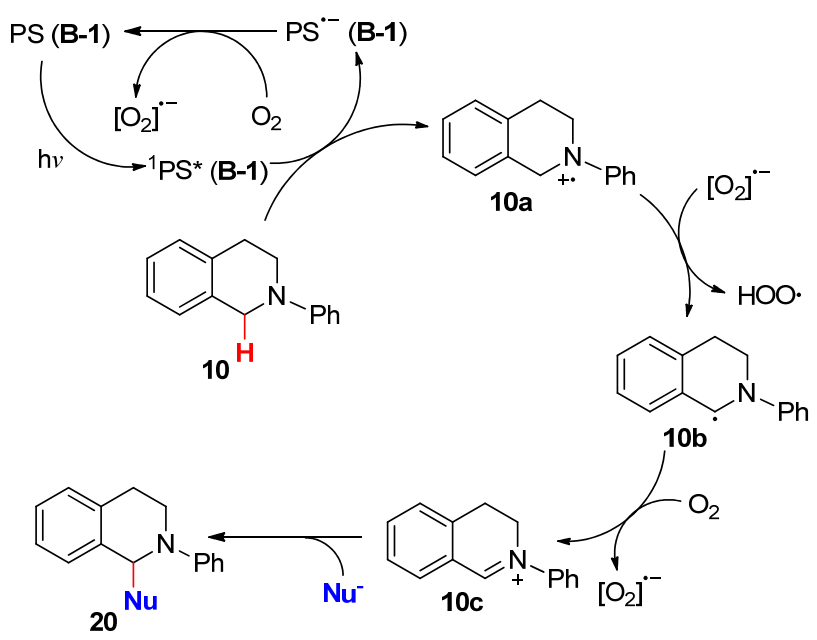

图式 $2 N$-苯基四氢异喹啉和亲核试剂的交叉脱氢偶联反应 机理

Scheme 2 Cross dehydrogenation coupling mechanism of $\mathrm{N}$-phenyltetrahydroisoquinoline and nucleophile

2015 年, Raston 等 ${ }^{[42]}$ 将 Rose Bengal 染料光催化的 $N$-芳基四氢异喹啉的亲核反应运用到微流体浴流装置 (VFD)当中, 开发了一种新型反应设备(Eq. 14). 该反应 具有时间短和产率高的优点, 且 VFD 坚固, 易于操作和 维护, 在流动过程中不会使化学物质造成通道反应器堵 塞, 有利于化学反应的控制.

2015 年, Zeitler 课题组 ${ }^{[43]}$ 报道了在 $\mathrm{CBrCl}_{3}$ 催化下, $N$-苯基四氢异喹啉转化成溴化亚胺盐, 再与亲核试剂硝
基甲烷或丙二酸二甲酯进一步反应得到目标产物(Eq. 15). 该催化体系反应条件温和、反应时间短，对亚磷酸 二乙酯和吲哚也有适用性, 为卤代化合物催化有机反应 提供了新思路.
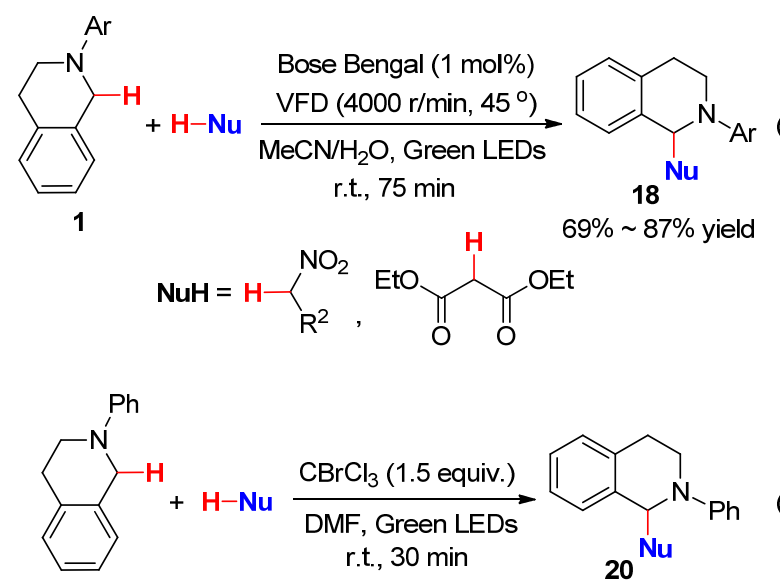

10 $91 \% \sim 98 \%$ yield

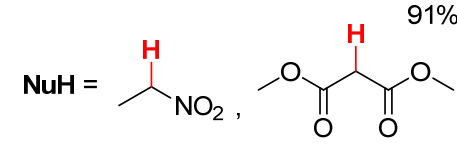

2016 年, Rios 课题组 ${ }^{[44]}$ 报道了通过交叉脱氢偶联构 建含氟结构单元的方法. 在绿光的照射下，以 Rose Bengal 染料作光敏剂, $\mathrm{Bu}_{4} \mathrm{NOAc}$ 作碱, $N$-取代四氢异喹 啉和氟代丙二酸酯在 $\mathrm{CHCl}_{3}$ 溶剂中进行交叉脱氢偶联 反应，以较高产率得到了新型含氟偶联产物(Eq. 16). 该 方法为合成具有良好的热稳定性、化学稳定性和抗氧化 性的含氟化合物提供了新途径，但是催化效率不高，反 应时间过长.

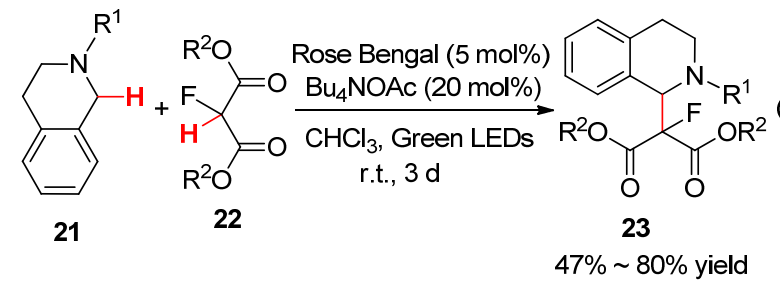

2017 年，张俊民课题组 ${ }^{[45]}$ 通过离子交换将 Rose Bengal 染料固定在聚二甲基硅氧烷(PDMS)海绵上，获 得了负载型催化剂 PDMS-RB 海绵, 并以其作为光催化 剂, 研究了叔胺和硝基烷烃和丙酮的交叉脱氢偶联反应 (Eqs. 17，18). 这种新型海绵催化剂在使用过程中表现 出优异的光催化活性，容易回收和再利用，且在重复使 用 15 次以后仍保持较高催化活性. 通过连续流反应器 更易按比例放大到工业化规模. 该方法操作简便，绿色 环保, 为探索高效率的新型非均相光催化剂开辟了新途 径.

同年，该课题组 ${ }^{[46]}$ 报道了一种新型双功能的有机 海绵光催化剂, 该催化剂通过将 Rose Bengal 染料光敏 

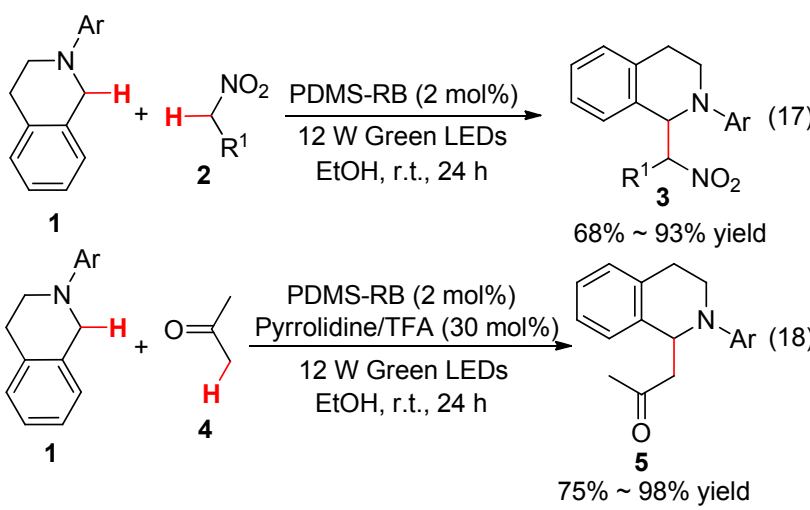

剂和烯胺有机催化剂同时固定在聚二甲基硅氧烷 (PDMS)海绵上所制得. 在该催化剂催化下, 叔胺与酮 在水中进行偶联, 获得了不错的产率(Eqs. 19 21). 将 PDMS sponge 1 的 $L$-脯氨酸甲酯部分用 $L$-脯氨酸钠盐替 换，制得了另一种手性双功能海绵光催化剂 PDMS sponge 2, 并在其催化下实现了叔胺与酮的不对称交叉 脱氢偶联反应, 该合成方法具有良好的对映选择性, 且 催化剂活性高, 环境友好.

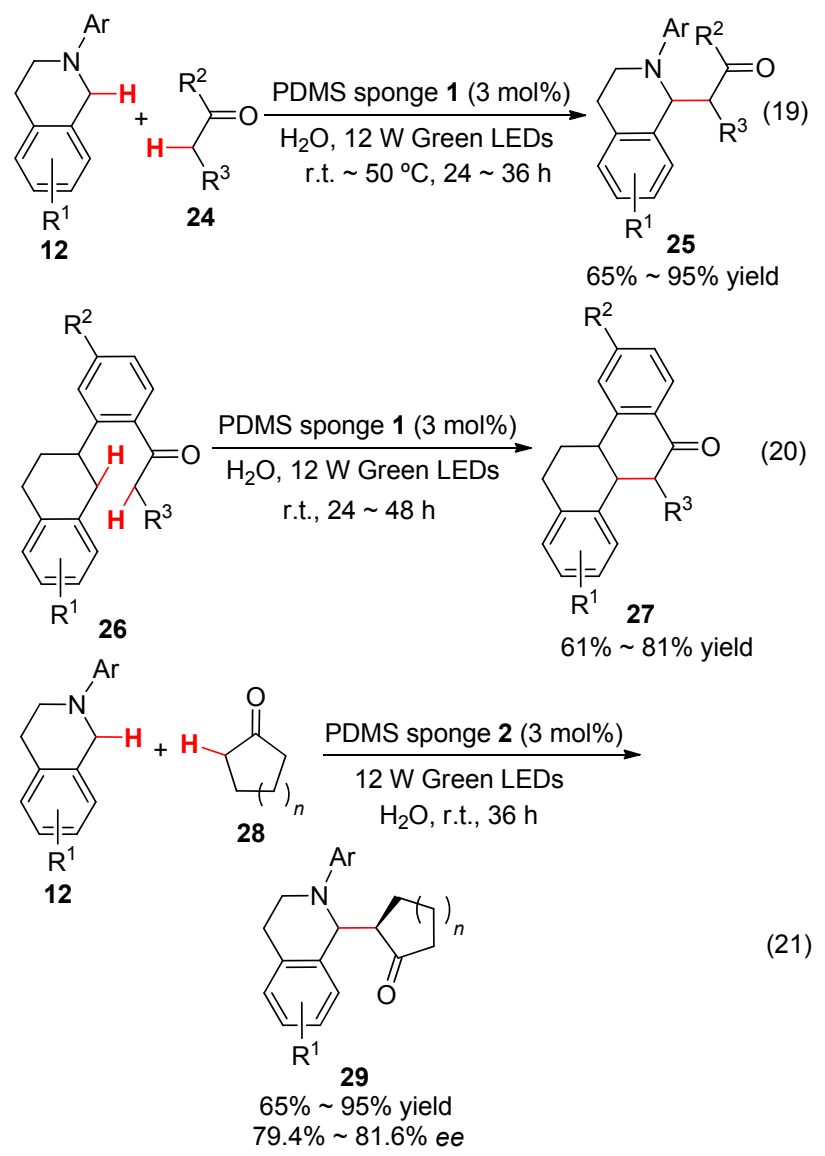

随后, 该课题组 ${ }^{[47]}$ 又将 Rose Bengal 染料通过离子 键固定到棉纤维上得到新型光催化剂 Cot-RB, 将其应 用于交叉脱氢偶联反应中, 得到了高产率产物(Eqs. 22,
23)。该催化剂利用丰富的天然材料棉纤维，表现出很 好的光催化活性，且具有可回收重复利用的优点. 此课 题组的这三项研究为开发更高效环保的负载型光催化 剂提供了广阔前景.

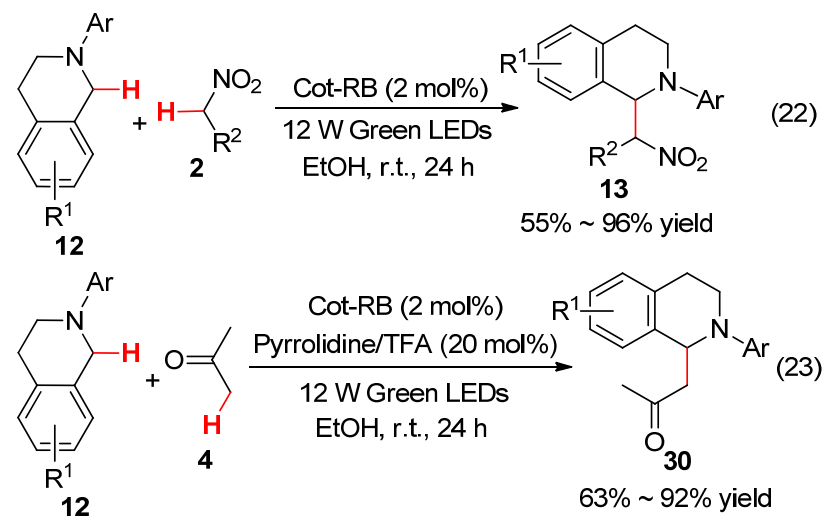

2017 年, 苏清课题组 ${ }^{[48]}$ 在加热条件下将 2,5-二甲氧 基对苯二甲酰肼与均苯三甲醛缩合，合成了基于腙的共 价有机骨架(COF)，并以其作为光催化剂，在 $45 \mathrm{~W}$ 的节 能灯照射下, 氧气作氧化剂, 研究了 $N$-芳基四氢喹啉和 亲核试剂的交叉脱氢偶联反应(Scheme 3). COF 材料具 有热稳定性良好、化学稳定性良好、可重复利用和底物 适用性广等优点, 为寻找安全、高效且环保的光催化剂 提供了应用前景.

次年，该课题组 ${ }^{[49]}$ 又通过直接缩聚合成了在聚合 物骨架中具有 $\mathrm{A}_{3} \mathrm{~B}_{2}$ 型供体-受体阵列的含二氟硼酸盐的 共轭有机聚合物(B-COP), 以其作为光催化剂, 在 $5 \mathrm{~W}$ 蓝光的照射下，氧气氛围中室温下进行反应(Scheme 3). 该催化剂具有无定形结构, 热稳定性好, 适用于各种底 物，且经 5 次重复利用后仍保持了良好活性. 相比之前 COF 催化剂，该体系缩短了反应时间且提高了产率.

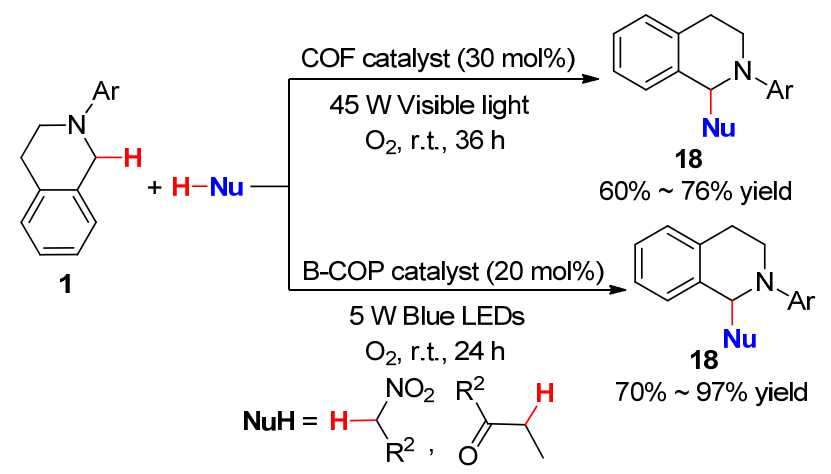

图式 $3 \mathrm{~N}$-芳基四氢喹啉和亲核试剂的交叉脱氢偶联反应 Scheme 3 Cross-dehydrogenation coupling reaction of $\mathrm{N}$-aryltetrahydroquinoline and nucleophiles

2018 年, 温小安等 ${ }^{[50]}$ 以 $N$-甲基-3(10H)-呋啶酮作为 光敏剂，在甲醇溶剂中，蓝光的照射下实现了 $N$-芳基四 氢异喹啉与各种亲核试剂交叉脱氢偶联反应(Eq. 24). 
机理研究表明, 该反应是单电子转移诱导的自由基过 程. 由于该光敏剂稳定且易制备的特点以及其独特的发 色团结构和光物理特性, 使得该催化体系具有高原子经 济性和良好的水溶性.

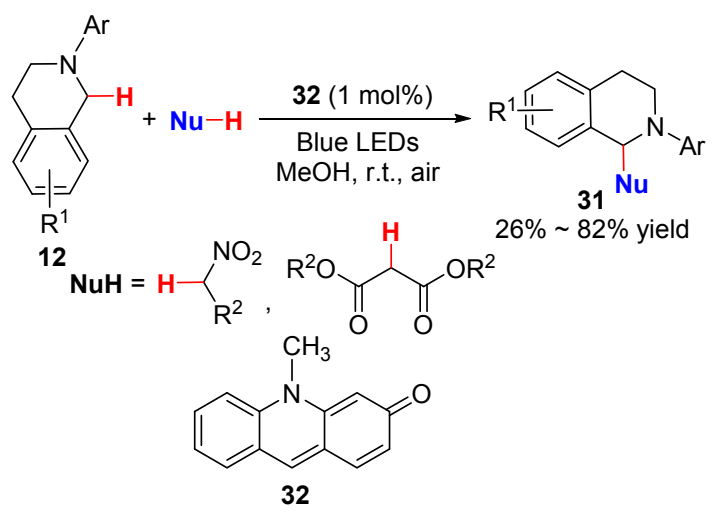

2018 年, 杨靖亚课题组 ${ }^{[51]}$ 报道了可见光介导下酮 的 $\alpha$-羟甲基化反应. 该反应通过自由基途径，以 Rose Bengal 染料作光敏剂, $\mathrm{K}_{2} \mathrm{CO}_{3}$ 作碱, 甲醇作羟甲基化试 剂, 室温下在水中实现交叉脱氢偶联(Eq. 25). 此方法合 成的 $\alpha$-着圣甲基酮具有良好的耐受性，过程操作简便，环 境友好.

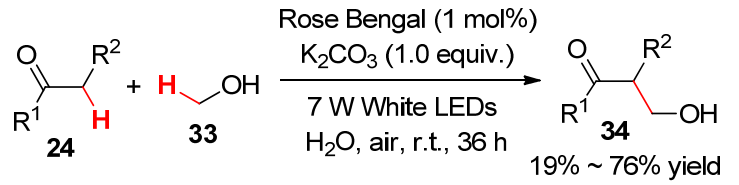

\section{$1.2 \mathrm{C}\left(\mathrm{sp}^{3}\right)-\mathrm{C}\left(\mathrm{sp}^{2}\right)$ 偶联}

2014 年, 周䂞课题组 ${ }^{[52]}$ 首次报道了可见光诱导下 叔胺和重氮化合物之间的交叉脱氢偶联反应. 在绿光的 照射下, 以 Rose Bengal 染料作光敏剂, 氧气作氧化剂, 室温下在二氯甲烷溶剂中反应 $12 \mathrm{~h}$ 得到 $\beta$-氨基- $\alpha$-重氮 化合物(Eq. 26). 所得的产物可以通过过渡金属进一步 选择性转化成 $N$-芳基-2,3-二氢苯并 $[d]$ 氮杂草. 该方法 具有广泛的底物范围, 且条件温和, 避免了过氧化物和 过渡金属使用下重氮化合物的分解, 为合成杂环化合物 提供了一条很好的途径.

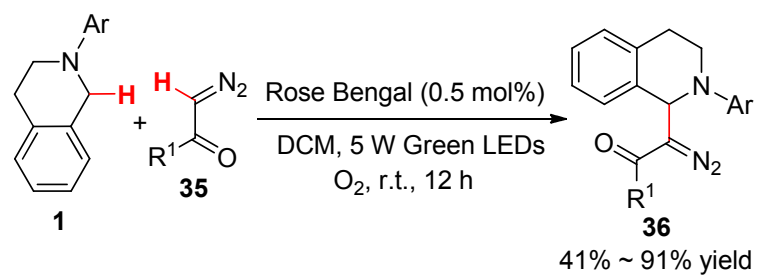

以 $N$-苯基四氢异喹啉(10)和 2-重氮基乙酸乙酯(37) 为例, 推测其反应机理如下: 首先, $\mathrm{RB}$ 在可见光的照射 下形成激发态 $\mathrm{RB}^{*}, \mathrm{RB}^{*}$ 通过单电子转移和叔胺形成 $N-$ 苯基四氢异喹啉自由基正离子 $10 \mathbf{a}$ 和 $\mathrm{RB}^{\circ-}$. 然后, $\mathrm{RB}^{\circ-}$
被氧气氧化得到氧气自由基负离子，同时再生 $\mathrm{RB}$ 用于 催化循环. 随后，氧气自由基负离子从 $10 \mathrm{a}$ 中夺取一个 氢原子生成亚胺离子 $10 \mathrm{c}$ 和氢过氧化物阴离子, 最后 $10 \mathrm{c}$ 和重氮化合物 37 结合生成中间体 $37 \mathrm{a}, 37 \mathrm{a}$ 被氢过氧 化物阴离子去质子化生成 $\mathrm{H}_{2} \mathrm{O}_{2}$ 和 $\alpha$-氨基重氮化合物 38 (Scheme 4).

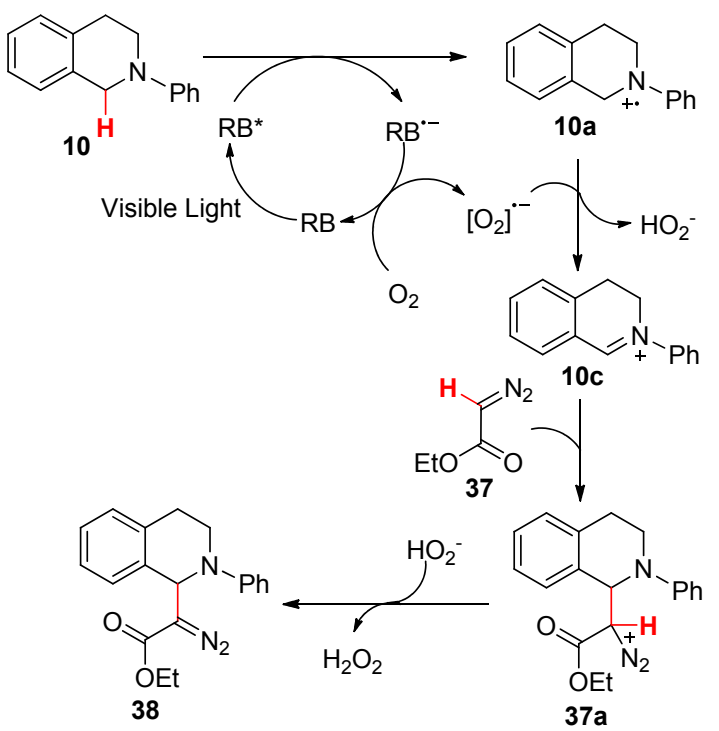

图式 $4 \mathrm{~N}$-苯基四氢异喹啉和 2-重氮基乙酸乙酯的交叉脱氢 偶联反应机理

Scheme 4 Cross dehydrogenation coupling mechanism of $\mathrm{N}$-phenyltetrahydroisoquinoline and ethyl 2-diazoacetate

2016 年, Shah 课题组 ${ }^{[53]}$ 报道了可见光促进下缺电 子芳烃和醚的 $\mathrm{C}-\mathrm{H}$ 官能化反应. 通过氢原子转移途径, 以 $\mathrm{K}_{2} \mathrm{~S}_{2} \mathrm{O}_{8}$ 作氧化剂, 室温下在水中实现了 $\mathrm{C}\left(\mathrm{sp}^{2}\right)$ $\mathrm{C}\left(\mathrm{sp}^{3}\right)$ 键的偶联(Scheme 5). 该反应体系对喹喔啉、吡 啶、萘醌和苯并噻唑等化合物也同样适用.

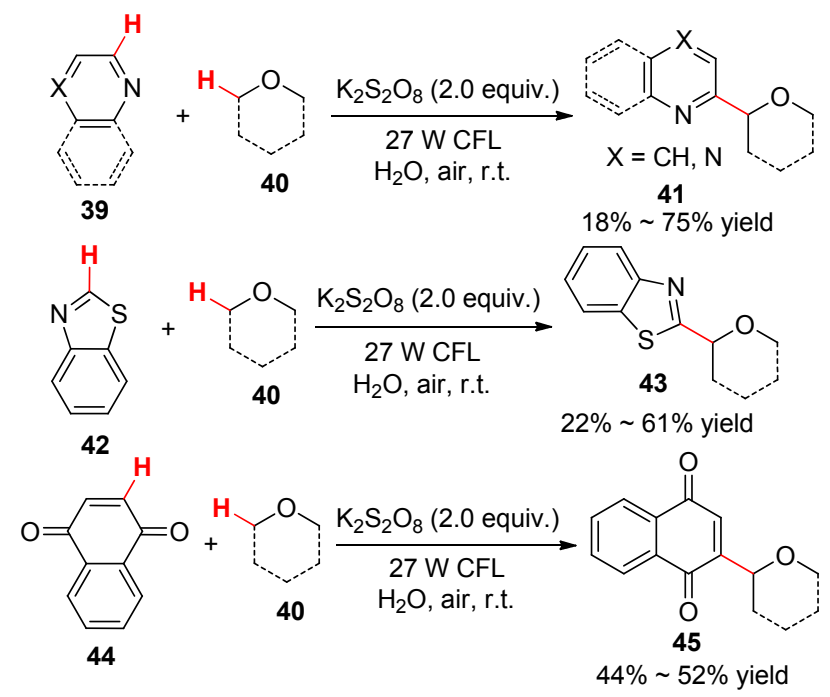

图 5 可见光诱导下缺电子芳烃和醚的 C-H 官能化反应 Scheme 5 Visible light-induced C-H functionalization of electron-deficient aromatics and ethers 
2016 年, 江智勇课题组 ${ }^{[54]}$ 报道了四氢- $\beta$-咔啉和四 氢异喹啉的烯烃化反应(Scheme 6). 该反应在光催化剂 DPZ、路易斯碱催化剂 $\beta$-ICD 和无机盐助催化剂的协同 催化作用下表现出优异的区域选择性和对映选择性.

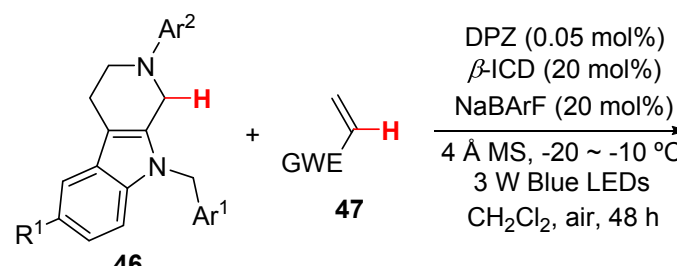

46<smiles>[R]c1ccc2c(c1)c1c(n2C[Al])[C@@H](C(=C)C([R16])C)N([Y17])CC1</smiles>

$$
\text { (20) }
$$

图式 6 四氢- $\beta$-咔啉和四氢异喹啉的氧化 $\mathrm{C}-\mathrm{H}$ 烯化反应 Scheme 6 Oxidative $\mathrm{C}$-H olefination of tetrahydro- $\beta$-carbolines and tetrahydroisoquinolines

2017 年, 张俊民课题组 ${ }^{[45]}$ 研究了负载型催化剂 PDMS-RB 海绵催化下, $N$-芳基四氢喹啉和重氮基乙酸 乙酯的交叉脱氢偶联反应(Eq. 27). 结合前面所述, 可见 负载型催化剂 PDMS-RB 海绵适用性广泛, 不仅能催化 实现 $\mathrm{C}\left(\mathrm{sp}^{3}\right)-\mathrm{C}\left(\mathrm{sp}^{3}\right)$ 键的构建, 还能催化得到 $\mathrm{C}\left(\mathrm{sp}^{2}\right)-$ $\mathrm{C}\left(\mathrm{sp}^{3}\right)$ 偶联产物.
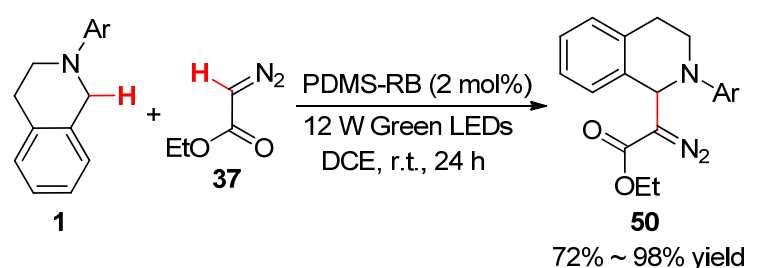

2017 年, Yamaguchi 课题组 ${ }^{[55]}$ 报道了光催化氧化下 由分子碘介导的杂芳烃与羰基化合物的偶联反应. 在 $22 \mathrm{~W}$ 紧凑型苂光灯的照射下, 以 $\mathrm{I}_{2}$ 作为催化剂, $\mathrm{K}_{3} \mathrm{PO}_{4}$

作碱，室温下反应 $20 \mathrm{~h}$ 实现了 $\mathrm{C}\left(\mathrm{sp}^{2}\right)-\mathrm{C}\left(\mathrm{sp}^{3}\right)$ 键的偶联 (Eq. 28). 同时也对这一自由基介导反应机理进行了阐 述. 该反应体系以廉价的分子碘作为催化剂，具有稳定 性高和环境友好等优点.

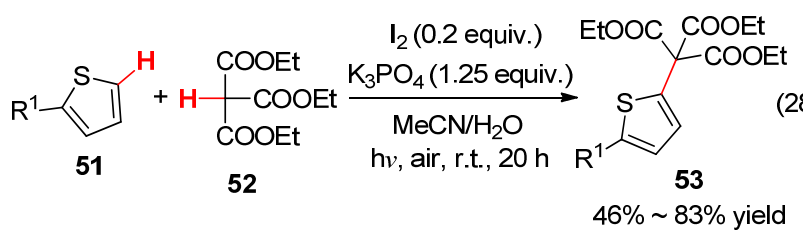

2018 年, 魏伟课题组 ${ }^{[56]}$ 报道了在蓝光的照射下，以 Rose Bengal 染料作光敏剂, 三乙烯二胺(DABCO)作碱, 叔丁基过氧化氢(TBHP)作氧化剂，室温下反应 $24 \mathrm{~h}$ ，实 现了 1-烷基喹喔啉-2(1H)-酮和醚和四氢噻吩的交叉脱 氢偶联反应(Eq. 29)。该方法产物区域选择性良好，底物 范围广泛, 通常产率较高, 对官能团的耐受性也比较好.

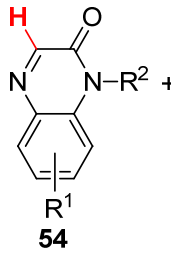

2018 年, Hajra 课题组 ${ }^{[57]}$ 报道了以蓝光为光源，以 Rose Bengal 染料为光敏剂, 在甲苯溶液中进行了咪唑 并 $[1,2-a]$ 吡啶(57)和 $N$-芳基四氢异喹啉、叔芳胺之间的 交叉脱氢偶联反应(Eqs. 30，31). 以咪唑并 $[1,2-a]$ 吡啶 (57)和 $N$-芳基四氢异喹啉(1)为例，推测其反应机理如 下：基态 $\mathrm{RB}$ 吸收光子后被转换为激发态 $\mathrm{RB}^{*} . \mathrm{RB}$ *将能 量转移到基态氧 ${ }^{3} \mathrm{O}_{2}$, 形成单线态氧 ${ }^{1} \mathrm{O}_{2} . N$ - 芳基四氢异 喹啉(1)被单线态氧氧化生成自由基正离子 $1 \mathrm{a}$ 和超氧自 由基负离子 $\mathrm{O}_{2}{ }^{--}$. 随后，进行氢原子转移生成亚胺离子 $1 \mathbf{b}$ 和 $\mathrm{HO}_{2}{ }^{-}$. 然后, $\mathbf{1 b}$ 加成到咪唑并 $[1,2-a]$ 吡啶 57 中得 到中间体 $57 \mathrm{a}$, 最后发生氢原子转移生成化合物 58 (Scheme 7). 该反应条件温和，反应时间短，副反应少， 反应效率高.

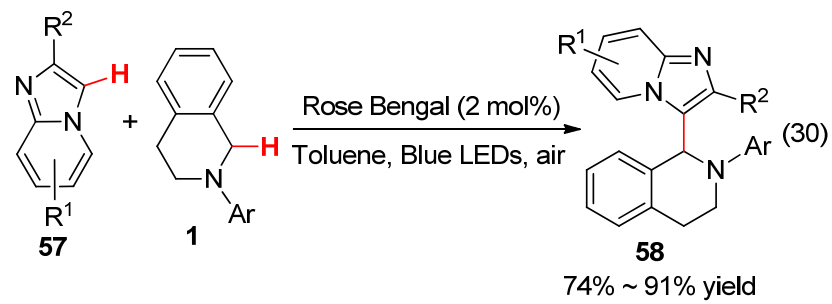



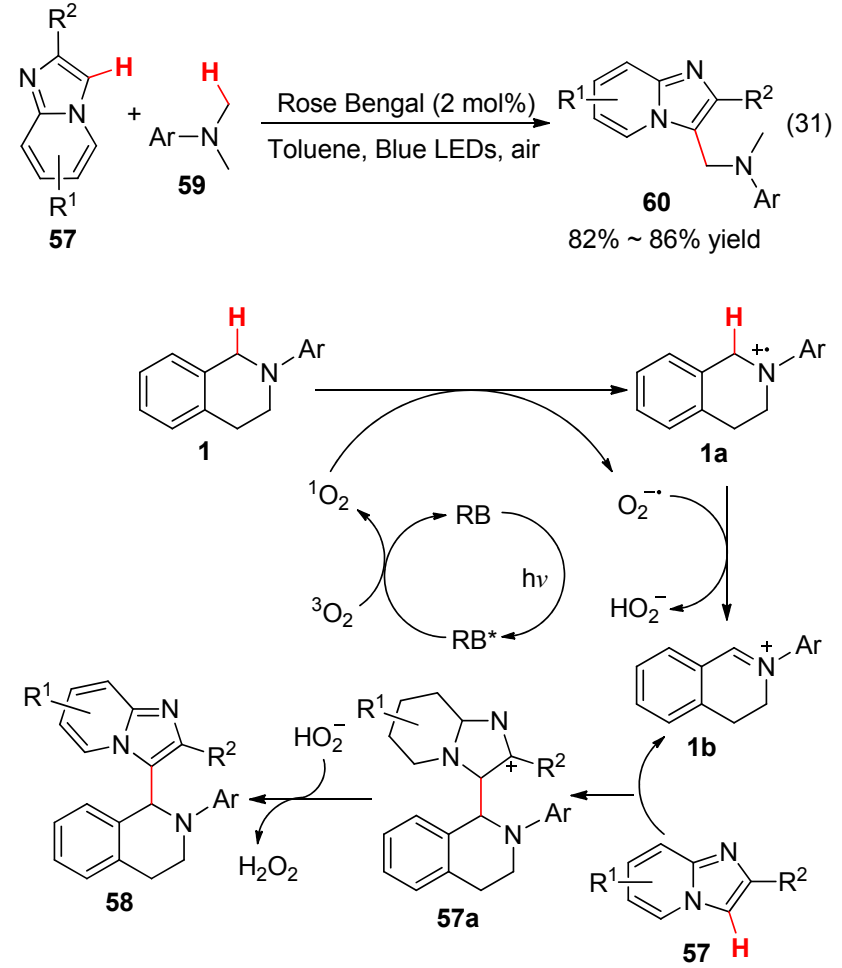

图式 $7 N$-芳基四氢异喹啉和咪唑并 $[1,2-a]$ 吡啶的交叉脱氢偶 联反应机理

Scheme 7 Cross dehydrogenation coupling mechanism of $\mathrm{N}$-aryltetrahydroisoquinoline and imidazo[1,2- $a]$ pyridine

随后, 该课题组 ${ }^{[58]}$ 利用类似催化体系进行了 2-烷 基- $2 H$-吲唑和醚、四氢噻吩的交叉偶联反应(Eq. 32). 该 反应可用于克规模合成, 为合成烷杂基化的 $2 H$-吲唑开 辟了温和简便的路线.

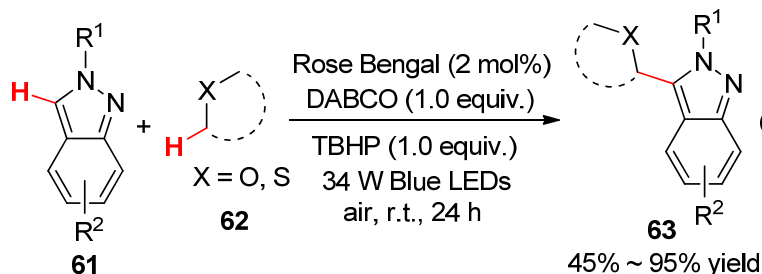

2018 年, 金灿等 ${ }^{[59]}$ 报道了 $N$-芳基甘氨酸酯与 $N$-取 代苯胺的光催化交叉脱氢偶联反应. 在蓝光的照射下, 以亚甲基蓝作为光催化剂, 无需额外的氧化剂和添加 剂, 实现了 $\mathrm{C}\left(\mathrm{sp}^{2}\right)-\mathrm{C}\left(\mathrm{sp}^{3}\right)$ 键的构建( Eq. 33). 反应过程 包括单电子转移和亲电子加成. 该合成方法适用的底物 范围广泛，条件温和且环境友好.

2018 年, 张元课题组 ${ }^{[60]}$ 报道了在光敏剂 Rh-6G 染 料和质子酸柠檬酸的催化作用下甘氨酸衍生物与吲哚 衍生物之间的 Friedel-Crafts 反应(Scheme 8). 机理研究 表明，该过程首先通过甘氨酸亚胺离子和吲哚交叉脱氢 偶联生成中间体 $67 \mathbf{a}$, 随后再进行第二次催化氧化最终<smiles>[R]OC(=O)C(Nc1c(C(Nc2ccc([R1])cc2)C(=O)O[R])ccc(N([R])[R])c1[R])c1ccc(N([R])[R])cc1[R]</smiles>

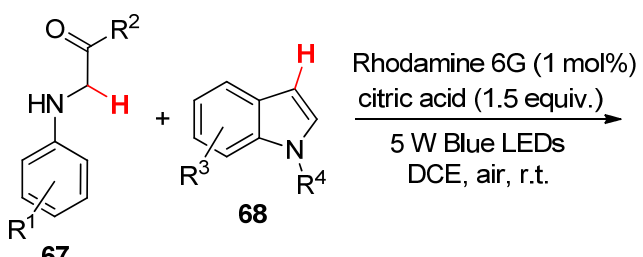

67
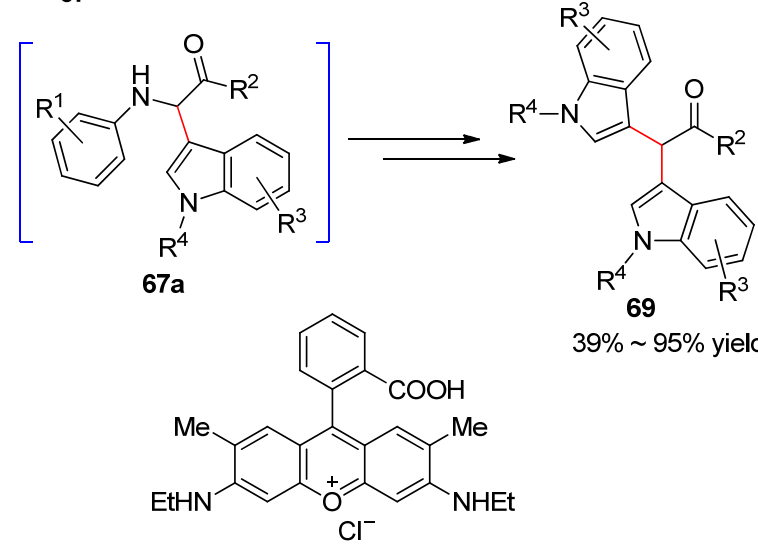

$39 \% \sim 95 \%$ yield

Rhodamine 6G

图式 8 可见光诱导下甘氨酸衍生物与吲哚的氧化交叉偶联 反应

Scheme 8 Visible light-induced oxidative cross-coupling of glycine derivatives with indoles

得到目标产物。该反应底物范围广泛，有良好的官能团 耐受性，为构建医药中间体二吲哚甲烷提供了新方法.

2019 年, 本课题组 ${ }^{[61]}$ 报道了无过渡金属催化下的 苯并噻唑的烷基化反应. 以蓝光作为光源, Eosin $\mathrm{Y}$ 染料 为光敏剂, $\mathrm{K}_{2} \mathrm{~S}_{2} \mathrm{O}_{8}$ 为氧化剂, 室温下反应 $24 \mathrm{~h}$, 进行自 由基介导的苯并噻唑和酰胺衍生物的交叉脱氢偶联反 应(Eq. 34). 相比 Ji 课题组 ${ }^{[62]}$ 苯并噻唑烷基化的方法(Eq. 35)，前者催化体系更简单，同时仍具有较好产率.

2019 年，雷爱文课题组 ${ }^{[63]}$ 报道了可见光诱导下醇 的 $\alpha-\mathrm{C}-\mathrm{H}$ 官能化反应. 可见光照射下，反应以氟试剂 作氧化剂，三氟乙酸(TFA)作添加剂，在氮气氛中实现 了杂芳烃和醇的交叉脱氢偶联反应(Eq. 36). 该方法无 

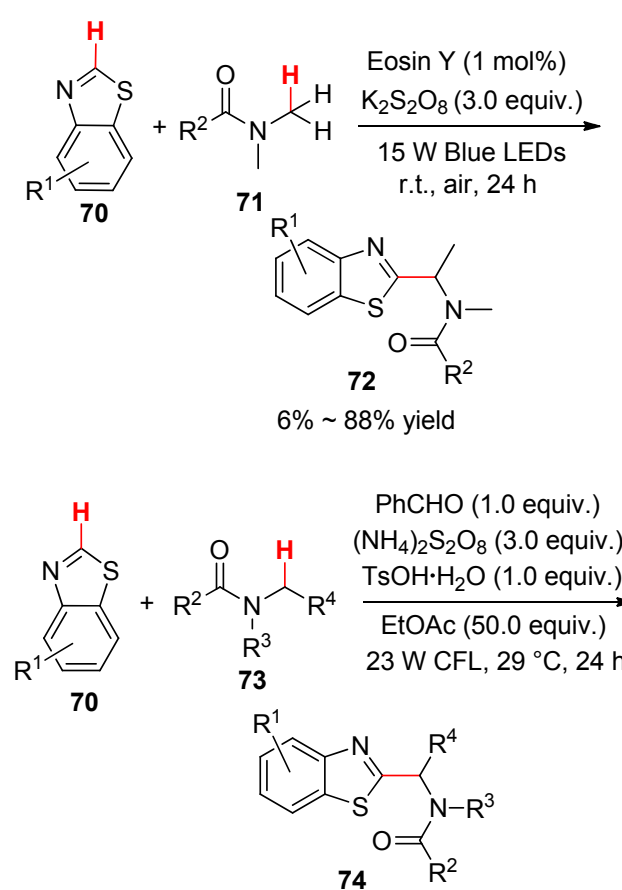

$25 \% \sim 88 \%$ yield

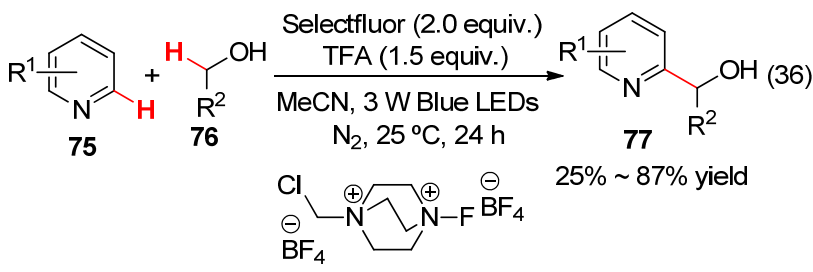

需光敏剂, 具有官能团耐受性, 且区域选择性良好, 为 向杂环引入活性醇羟基提供了新方法. 随后, 该课题 组 ${ }^{[64]}$ 也报道了在氟试剂/TFA 催化体系下, 室温条件下 杂芳烃与环烷烃、梄等的 $\mathrm{C}\left(\mathrm{sp}^{3}\right)-\mathrm{H}$ 芳基化反应(Eq. 37).

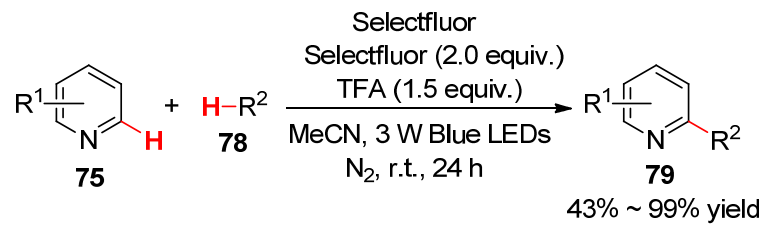

2019 年, 李朝军课题组 ${ }^{[65]}$ 以双乙酰(2,3-丁二䣳)作 光敏剂, 在室温条件下实现了交叉脱氢 Minisci 烷基化 反应(Scheme 9). 机理研究表明, 活化的 $\mathrm{C}\left(\mathrm{sp}^{3}\right)-\mathrm{H}$ 底物 和双乙酰之间发生了氢原子转移, 其中双乙酰为“无痕” 氢原子提取剂. 此外, 在二叔丁基过氧化物(DTBP)的辅 助下, 该反应可通过双乙酰介导的能量转移扩展到脂肪 族的强 $\mathrm{C}-\mathrm{H}$ 键. 该方法具有很好的稳健性, 能官能化 尼古丁、薄荷醇和丙氨酸衍生物等复杂分子.

\section{$1.3 \mathrm{C}\left(\mathrm{sp}^{2}\right)-\mathrm{C}\left(\mathrm{sp}^{2}\right)$ 偶联}

2016 年, $\mathrm{Ji}$ 等 ${ }^{[61]}$ 提出了光激发下苯甲醛介导 $\left(\mathrm{NH}_{4}\right)_{2} \mathrm{~S}_{2} \mathrm{O}_{8}$ 分解的自由基机理. 在家庭 $23 \mathrm{~W}$ 紧凑型苂

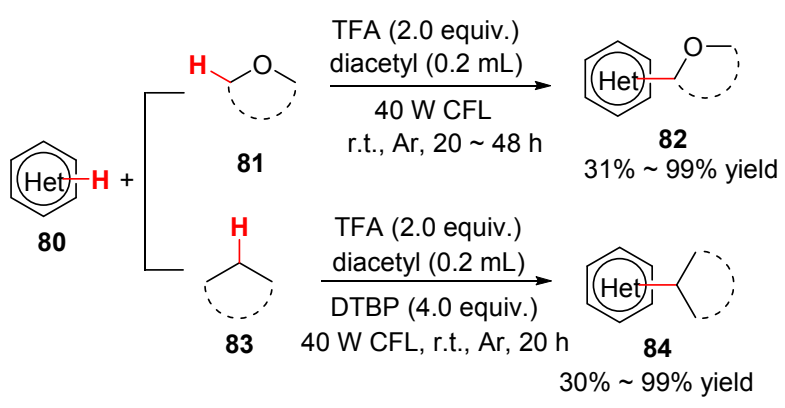

图式 9 可见光催化下杂芳烃的 Minisci 烷基化反应 Scheme 9 Visible light-induced Minisci alkylation of heteroaromatics

光灯 (CFL)照射下, $\left(\mathrm{NH}_{4}\right)_{2} \mathrm{~S}_{2} \mathrm{O}_{8}$ 作氧化剂, 对甲苯磺酸一 水合物 $\left(\mathrm{TsOH} \cdot \mathrm{H}_{2} \mathrm{O}\right)$ 作添加剂, 实现了苯甲醛催化下唑 类杂环化合物与甲酰胺的交叉脱氢偶联反应(Scheme $10)$. 该反应构建了新的 $\mathrm{C}\left(\mathrm{sp}^{2}\right)-\mathrm{C}\left(\mathrm{sp}^{2}\right)$ 键, 有助于促进 酰胺衍生物的 $\alpha$-芳基化反应.

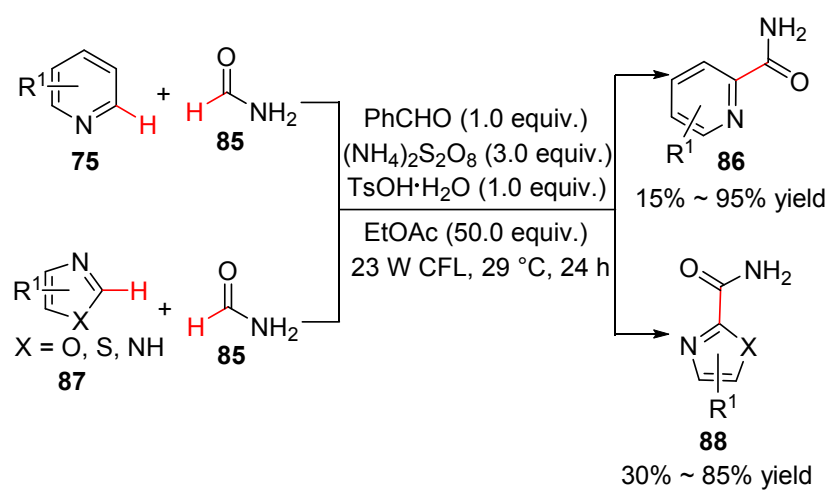

图式 10 苯甲醛催化下含氮杂环化合物与甲酰胺的交叉脱氢 偶联反应

Scheme 10 Cross dehydrocoupling reaction of nitrogen-containing heterocycles and formamide by benzaldehyde catalysis

以苯并噻唑 42 与甲酰胺 85 为例, 推测其反应机理 如下: 苯甲醛在可见光的照射下形成 I 和 II, 其促进 $\left(\mathrm{NH}_{4}\right)_{2} \mathrm{~S}_{2} \mathrm{O}_{8}$ 的分解，生成 $\mathrm{SO}_{4}{ }^{-}$和中间体 III、IV. 随后， $\mathrm{SO}_{4}{ }^{-}$从生酰胺 85 中夺取一个氢原子生成自由基 $85 \mathrm{a}$, 亚胺 $85 \mathrm{a}$ 与 $\mathrm{C}-2$ 位质子化的苯并噻唑 42a 发生亲核加成, 然后再进行去质子化和氧化, 得到目标产物 89. 其中中 间体 III 和 IV 参与氧化步骤, 从而再生苯甲醛(Scheme 11).

2018 年, 雷爱文课题组 ${ }^{[66]}$ 报道了光催化下的 $\mathrm{C}\left(\mathrm{sp}^{2}\right)$ - $\mathrm{H}$ 酰基化反应. 反应以叔丁基过氧化氢(TBHP) 作氧化剂, TFA 作添加剂, 醛作酰基源, 在氮气氛围中 室温反应 $24 \mathrm{~h}$ 实现了异喹啉的酰基化(Eq. 38). 该催化 体系无需光催化剂的作用即可以良好的产率得到交叉 脱氢偶联产物. 

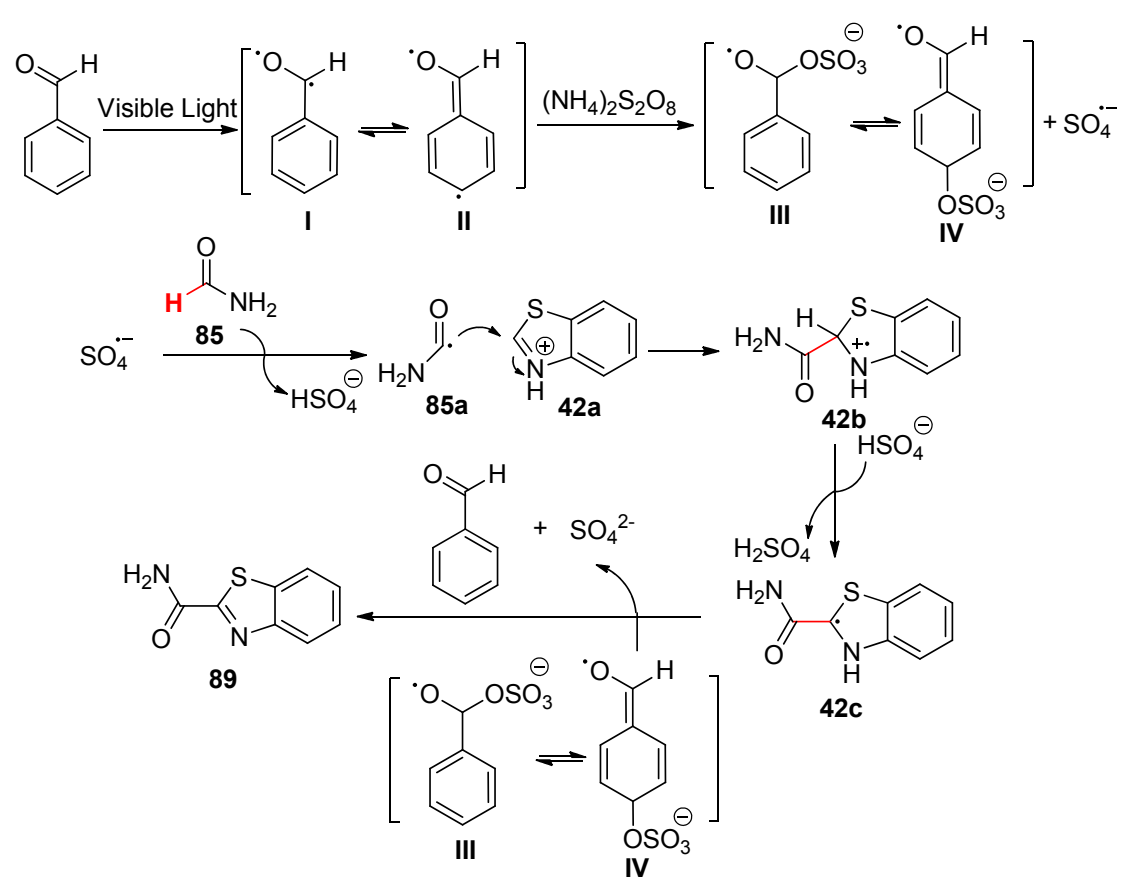

图式 11 苯并噻唑和甲酰胺的交叉脱氢偶联反应机理

Scheme 11 Cross dehydrogenation coupling mechanism of benzothiazole and formamide

\section{$2 \mathrm{C}-\mathrm{N}$ 偶联反应}

\section{1 含 $\mathrm{N}$ 化合物作为亲核试剂}

2012 年, 肖文精等 ${ }^{[67]}$ 利用有机染料 $\mathrm{Na}_{2}$-Eosin $\mathrm{Y}$ 代 替 $\operatorname{Ir}(\mathrm{ppy})_{2}(\mathrm{dtb}-\mathrm{bpy}) \mathrm{PF}_{6}$ 金属催化剂, $t$-BuOK 作碱, 在光 照下实现了分子内交叉脱氢偶联, 得到了产率良好的稠 杂环产物(Eq. 38). 该方法条件温和, 提供了一种有机染 料光敏剂催化下合成杂环化合物的新方法.
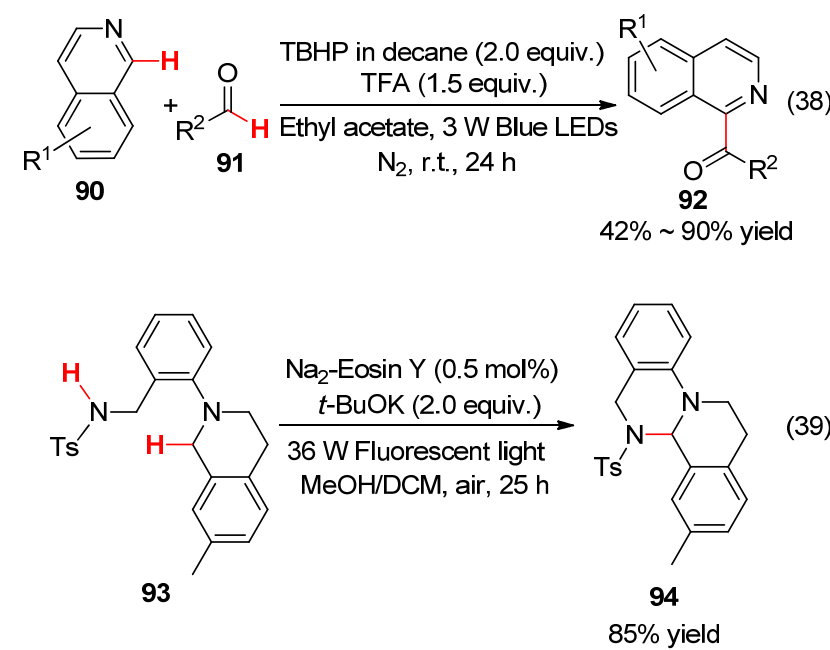

2013 年, Tan 课题组 ${ }^{[68]}$ 报道了氨基醇和烯烃的交叉 脱氢偶联反应. 反应在 $11 \mathrm{~W}$ 家用苂光灯照射下, 以 Rose Bengal 染料作光敏剂, 加入一定量的添加剂吡啶 以提高反应速率和产率(Eqs. 40, 41). 该方法操作简单, 环境友好, 可以避免金属催化剂及其他氧化剂引起的环
境污染. 但是在进行非末端烯烃的烯丙基胺化反应的时 候，易生成异构体混合物.

$$
\text { }
$$

2014 年, Leow 课题组 ${ }^{[69]}$ 报道了利用吩嗪盐催化芳 香醛衍生物的氧化酰胺化. 在可见光的照射下, 以吩嗪 乙硫酸盐作催化剂, 室温下进行反应(Eq. 42). 该方法原 子经济性高, 底物范围广, 为醛的直接酰胺化反应提供 了新思路.

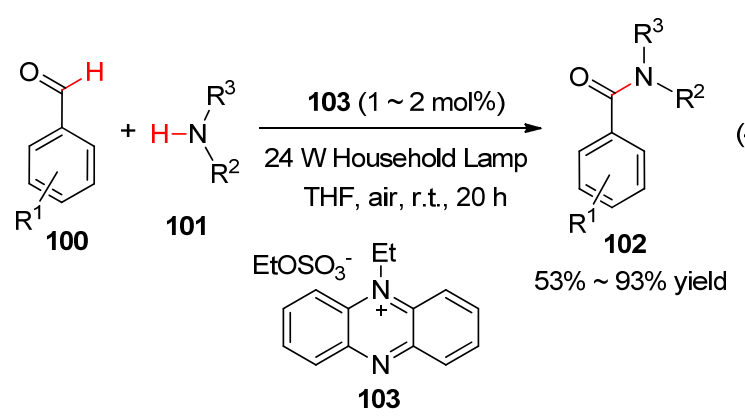

吩嗪盐是众所周知的电子受体, 以芳香醛 100 和胺 101 为例, 推测其反应机理如下 Scheme 12, 吩嗪盐 103 


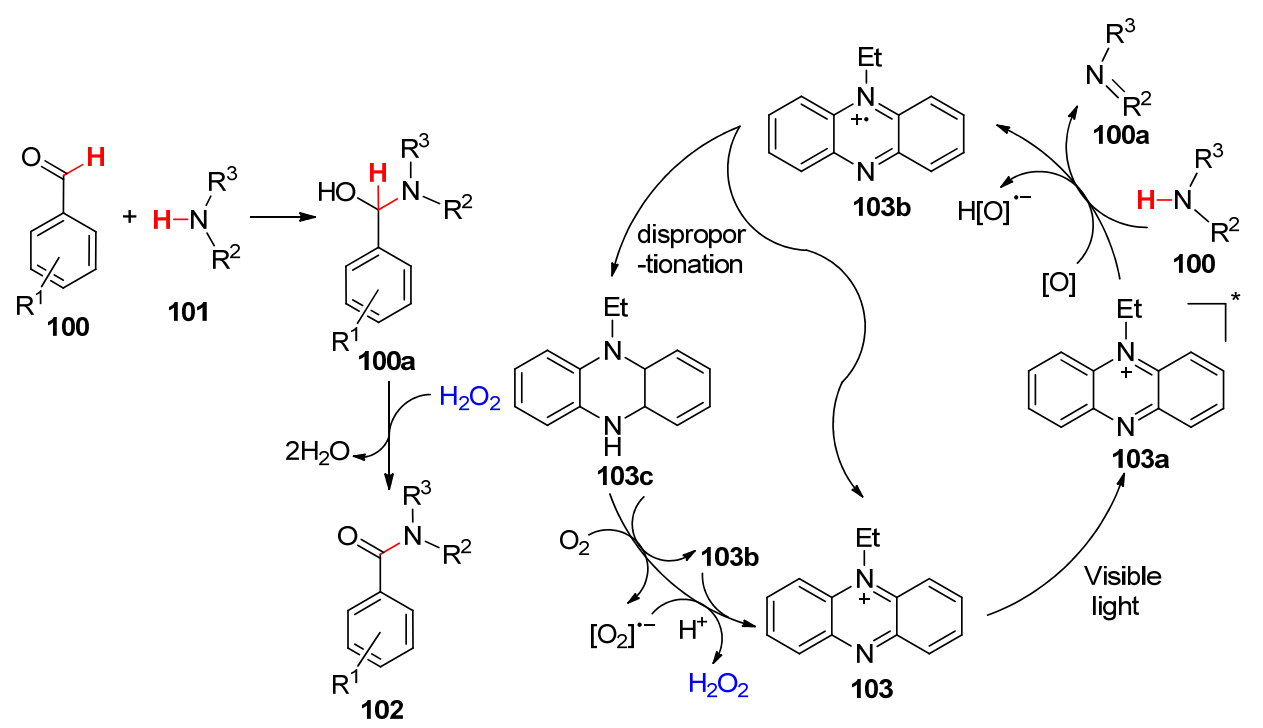

图式 12 吩嗪盐催化芳香醛酰胺化的反应机理

Scheme 12 Reaction mechanism of phenazine salt catalyzing amidation of aromatic aldehydes

在可见光的照射下形成激发态 103a, 随即与胺 101 发生 单电子转移生成自由基正离子化合物 $103 \mathrm{~b}$ 和亚胺 $101 \mathrm{a}$, 然后 $103 b$ 发生歧化反应生成 5-乙基-5,10-二氢吩嗪 $(103 c)$ 和吩嗪盐 103 , 随后 $103 c$ 被氧气氧化再生光催化 剂 103, 同时伴随产生的 $\mathrm{H}_{2} \mathrm{O}_{2}$ 氧化半缩醛胺 $100 \mathrm{a}$ 成目 标产物酰胺 102.

2015 年, Pandey 等 ${ }^{[70]}$ 报道了可见光催化下苄基 $\mathrm{C}\left(\mathrm{sp}^{3}\right)-\mathrm{H}$ 的直接胺化. 以 9,10 -二氰基葸(DCA)作为光 催化剂, 酰胺作氮源, 实现了分子间和分子内的偶联反 应(Eqs. 43, 44). 该催化体系无需外部氧化剂的参与, 绿 色环保, 具有广泛的底物范围和优异的区域选择性.

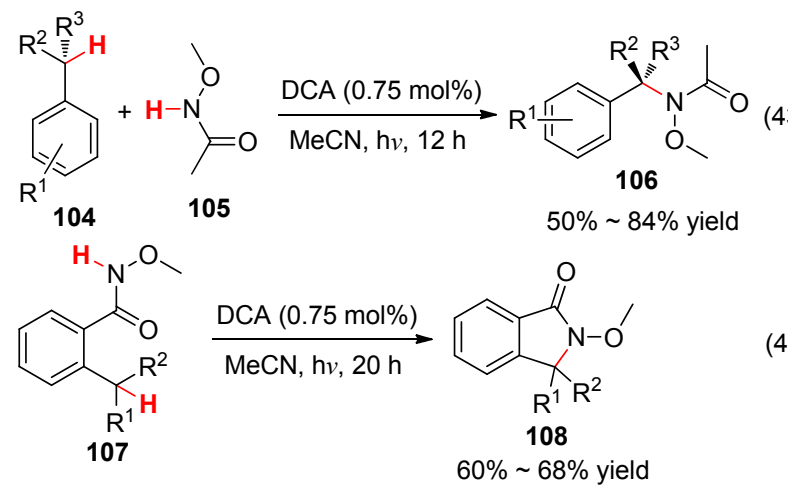

2015 年, Nicewicz 等 ${ }^{[71]}$ 报道了鲐定染料选择性催化 的芳基 $\mathrm{C}\left(\mathrm{sp}^{2}\right)-\mathrm{H}$ 胺化. 在 $455 \mathrm{~nm}$ 波长的蓝光照射下, 以 $\left[(t-\mathrm{Bu})_{2}-\mathrm{Mes}^{+}-\mathrm{Acr}-\mathrm{Ph}\right]\left[\mathrm{BF}_{4}{ }^{-}\right]$作光催化剂, 2,2,6,6-四甲 基哌啶一氮-氧化物(TEMPO)作助催化剂, 在氧气氛围中 进行反应(Eq. 45). 其中吅啶催化剂促进了关键性中间 体芳基阳离子的形成, 且可通过简单的过滤实现催化剂 回收再利用. 该反应实现了芳烃与各种杂环叔胺的偶联
反应，包括吡唑、三唑等相关衍生物，底物范围广泛且 具有较高的区域选择性和原子经济性. 随后, 该课题 组 ${ }^{[72]}$ 以伯胺作为氮源, 在 $455 \mathrm{~nm}$ 的光源下, 以鲐啶染 料 $\left[(t-\mathrm{Bu})_{2}-\mathrm{Mes}^{+}-\mathrm{Acr}-\mathrm{Ph}\right]\left[\mathrm{BF}_{4}{ }^{-}\right]$和 $\left[\mathrm{Me}_{2}-\mathrm{Mes}^{+}\right.$-Acr-Ph]$\left[\mathrm{BF}_{4}{ }^{-}\right]$作为光催化剂, 实现了芳烃的 $\mathrm{C}\left(\mathrm{sp}^{2}\right)-\mathrm{H}$ 胺化(Eq. 46). 该反应条件温和, 且具有较好的官能团耐受性.

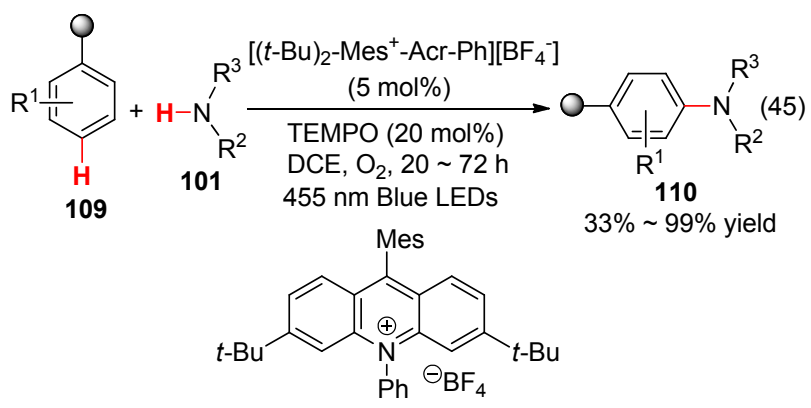
$\left[(t-\mathrm{Bu})_{2}-\mathrm{Mes}^{+}-\mathrm{Acr}-\mathrm{Ph}^{-}\left[\mathrm{BF}_{4}^{-}\right]\right.$

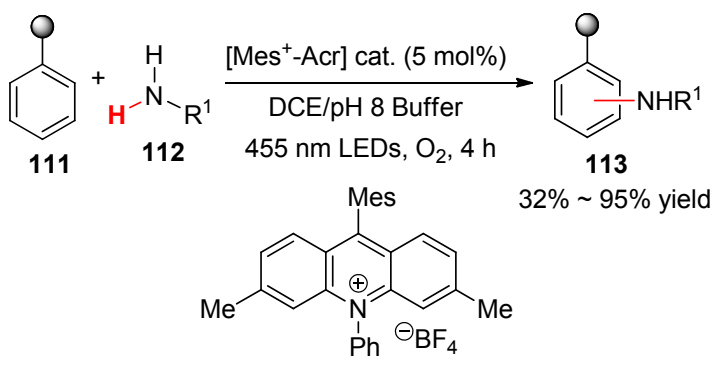

$\left[\mathrm{Me}_{2}-\mathrm{Mes}^{+}-\mathrm{Acr}-\mathrm{Ph}\right]\left[\mathrm{BF}_{4}^{-}\right]$

2016 年, König 等 ${ }^{[73]}$ 报道了鲐定染料催化下磺酰胺 和吡咯的偶联反应. 通过一锅法在 $455 \mathrm{~nm}$ 的可见光照 射下, 以 $\left[\mathrm{Acr}^{+}-\mathrm{Mes}-\mathrm{Me}\right]\left[\mathrm{ClO}_{4}{ }^{-}\right]$作光催化剂, $\mathrm{NaOH}$ 作碱, 氧气氛围下在乙腈和水混合溶剂中反应得到偶联产物 (Eq. 47). 该催化体系条件温和，具有良好的官能团耐受 
性和区域选择性, 实现了杂芳烃的磺酰胺化, 可有效地 应用于医药化学领域. 但是对于茮基或者苯基吡咯反应 时产率较低, 可能由于其亲核性低不利于转化.

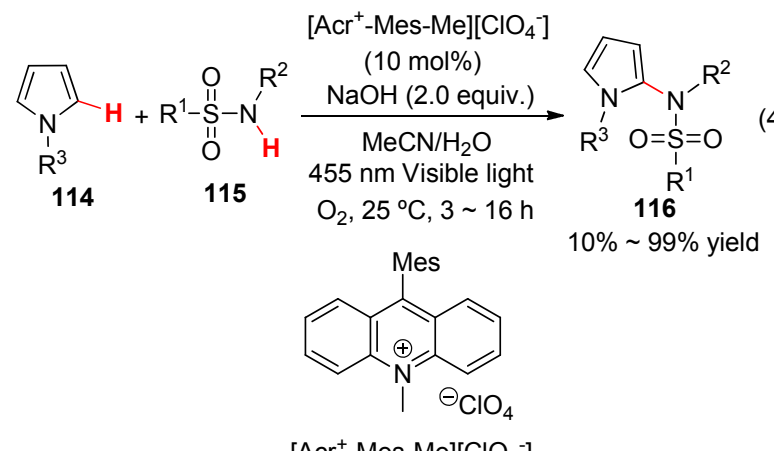

2017 年, Murakami 等 ${ }^{[74]}$ 研究了在蓝光的照射下, 以 2,3-二氯-5,6-二氰基对苯醌(DDQ)为光敏剂, 䒺、噁唑和 1,4-萗醌等芳烃与磺酰亚胺之间的 $\mathrm{C}-\mathrm{H} / \mathrm{N}-\mathrm{H}$ 偶联反 应(Eq. 48). 该方法操作简便, 提供了一条芳烃磺酰胺化 的有效途径. 同年, 雷爱文等 ${ }^{[75]}$ 以 DDQ 作光敏剂, 亚硝 酸叔丁酯(TBN)作电子转移介质, 实现了噻吩和吡唑和 吲唑等唑类化合物的 $\mathrm{C}\left(\mathrm{sp}^{2}\right)-\mathrm{N}$ 偶联(Eq. 49). 与单一使 用 DDQ 作催化剂相比, 该方法大大缩短了反应时间. 随后, König 课题组 ${ }^{[76]}$ 分别以 Boc-胺、氨基甲酸酯、吡 唑、磺酰亚胺和脲作为氮源, 在 $\mathrm{DDQ} / \mathrm{TBN}$ 催化体系中, 进行了取代苯的胺化反应(Eq. 50).

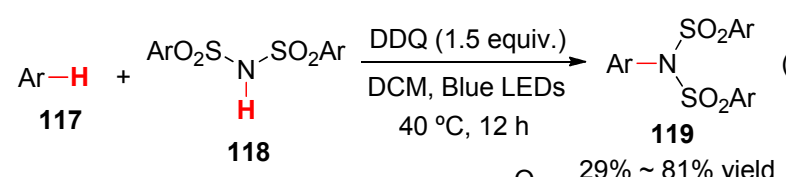<smiles>[R1]c1cccc2ccc([Al])cc12</smiles><smiles>O=c1cc(-c2ccccc2)oc2ccccc12</smiles>

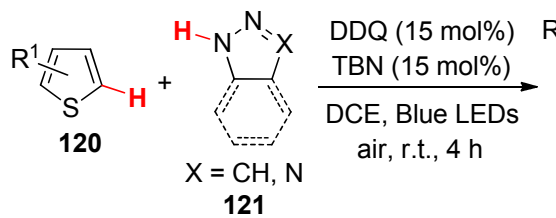<smiles>[R1]c1ccc(-n2nnc3ccccc32)s1</smiles>

122 $33 \% \sim 95 \%$ yield

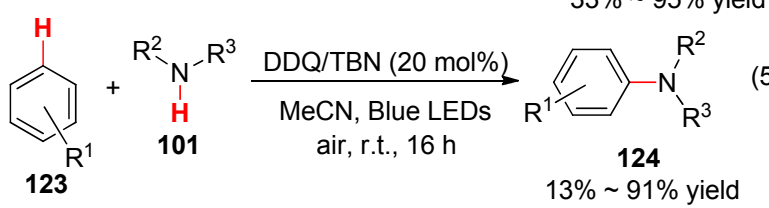

\section{2 含 $\mathrm{N}$ 化合物形成 $\mathrm{N}$ 自由基}

2016 年, Muñiz 课题组 ${ }^{[77]}$ 报道了分子内芳基 $\mathrm{C}-\mathrm{H}$ 官能化反应. 利用分子碘和高价碘 $\mathrm{PhI}\left(\mathrm{O}_{2} \mathrm{CAr}\right)_{2}$ 试剂组 合的催化体系, 温和的条件下进行芳烃分子内胺化 (Scheme 13). 在光照下形成以 $\mathrm{N}$ 为中心的自由基, 随后
单电子转移再去质子化得到环状磺酰胺. 该方法也适用 于含有链硅烷的芳烃，具有较好的官能团耐受性，以价 廉易得的分子碘作为催化剂，环境友好易于处理，符合 绿色化学的要求.
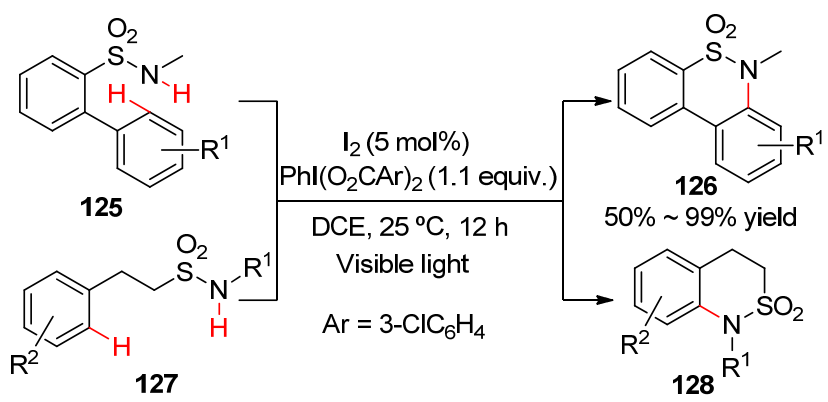

$51 \% \sim 99 \%$ yield

图式 13 可见光催化下芳烃分子的内胺化反应

Scheme 13 Visible light-induced intramolecular amination of aromatics

2016 年, 夏吾昫课题组 ${ }^{[78]}$ 报道了在酚和环状胺分 子之间的交叉脱氢偶联反应. 在蓝光的照射下, 以 $\mathrm{K}_{2} \mathrm{~S}_{2} \mathrm{O}_{8}$ 作为氧化剂, 室温下在乙腈溶剂中进行反应实现 了 $\mathrm{C}-\mathrm{N}$ 键的构建( Eq. 51). 该过程中酚 129 和胺 130 均 被 $\mathrm{K}_{2} \mathrm{~S}_{2} \mathrm{O}_{8}$ 氧化成自由基 129c 和 130b, 随后发生自由基 间的交叉偶联反应得到中间体 129d, 最后发生异构化 得到最终产物 131(Scheme 14). 该方法无需催化剂参与,
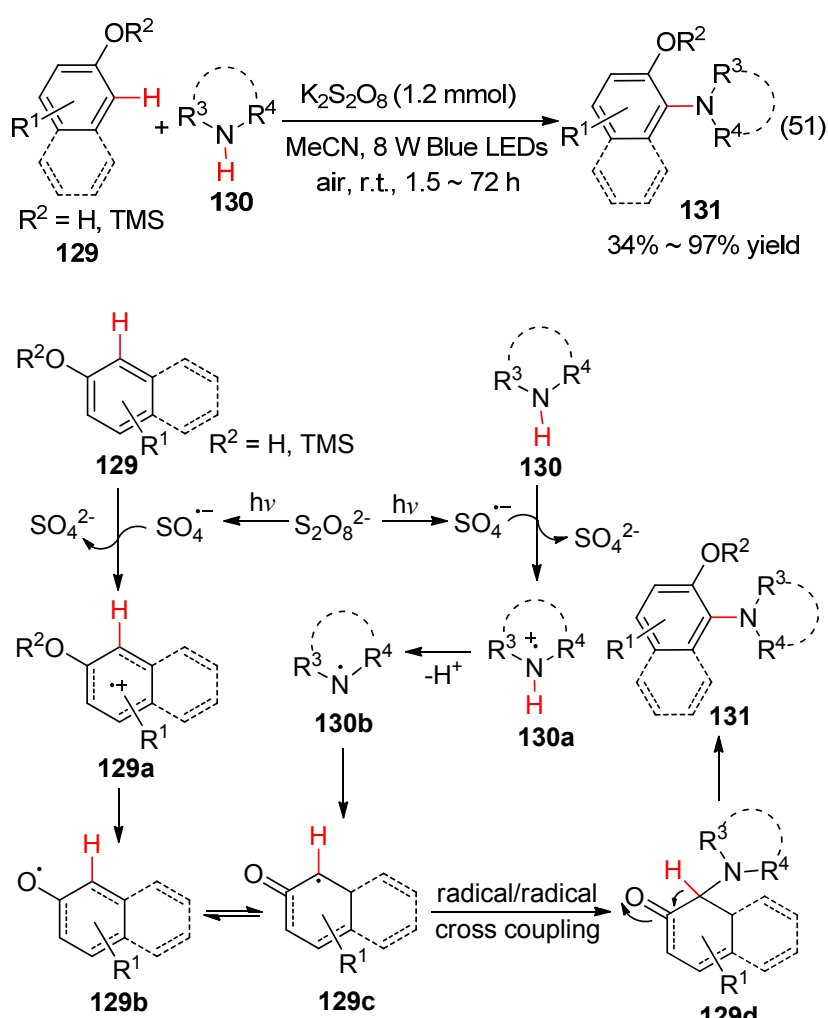

图式 14 酚和胺的交叉脱氢偶联反应机理

Scheme 14 Cross dehydrogenation coupling reaction mechanism of phenols and amines 
也不需要底物预活化，反应条件温和，且产物具有单一 的区域选择性.

次年, 该课题组 ${ }^{[79]}$ 又报道了酚和非环状二芳基胺 分子间的交叉脱氢偶联反应. 在蓝光的照射下, 以 $\left(\mathrm{NH}_{4}\right)_{2} \mathrm{~S}_{2} \mathrm{O}_{8}$ 作为氧化剂, 加入有机光催化剂(OPC), 室 温下在邻二氯乙烷溶剂中实现了 $\mathrm{C}\left(\mathrm{sp}^{2}\right)-\mathrm{N}$ 键的形成 (Eq. 52). 机理研究表明, 此反应过程是通过自由基间的 偶联反应进行的. 该反应条件温和, 具有广泛的底物范 围和高效的区域选择性，可用于构建三芳基胺单元.

$$
\text { } \frac{\left(\mathrm{NH}_{4}\right)_{2} \mathrm{~S}_{2} \mathrm{O}_{8}(0.6 \mathrm{mmol})}{8 \mathrm{~W} \text { Blue LEDs }}
$$

2017 年, Itoh 课题组 ${ }^{[80]}$ 报道了 1-甲基-2-烷基吲哚的 $\mathrm{C}-\mathrm{H}$ 胺化反应, 反应以邻苯二甲酰亚胺为氮源, 在 21 $\mathrm{W}$ 苂光灯的照射下, 以 2-叔丁基蒽醌(2-t-Bu-AQN)作催 化剂, $\mathrm{K}_{2} \mathrm{CO}_{3}$ 作碱(Eq. 53). 该反应过程中在吲哚的 C-2 位置产生的自由基是其关键中间体，因此当取代基为给 电子基团时产率明显提高.

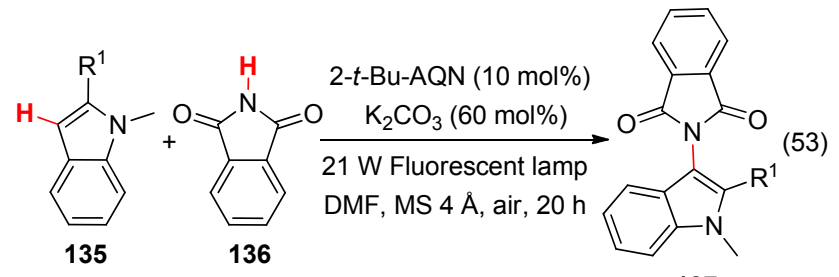

137

$29 \% \sim 93 \%$ yield

2017 年, 雷爱文课题组 ${ }^{[81]}$ 报道了蓝光照射下, 以 $\left[\mathrm{Acr}^{+}-\mathrm{Mes}-\mathrm{Me}\right]\left[\mathrm{ClO}_{4}^{-}\right]$为光催化剂, 四氢呋喃的 $\alpha-$ $\mathrm{C}\left(\mathrm{sp}^{3}\right)-\mathrm{H}$ 官能化反应(Eq. 54). 该方法耐受各种唑类衍 生物. 同年, Adimurthy 课题组 ${ }^{[82]}$ 报道了相同催化剂催化 下, 喹啉酰胺(C-5)和咪唑并吡啶(C-3) 的区域选择性 $\mathrm{C}\left(\mathrm{sp}^{2}\right)-\mathrm{H}$ 胺化(Scheme 15), 也具有很好的官能团耐受 性, 但是与前者相比, 需要氧化剂参与, 氩气保护, 而 且反应时间长。

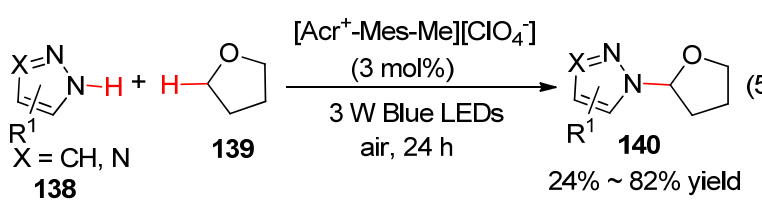

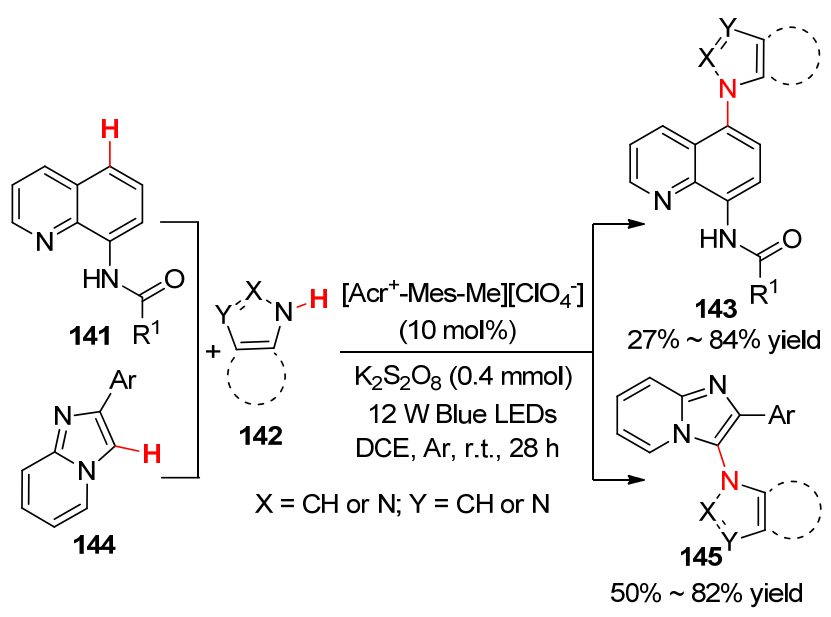

图式 15 喹啉酰胺和咪唑并吡啶的选择性 $\mathrm{C}-\mathrm{H}$ 胺化反应 Scheme 15 Selective $\mathrm{C}-\mathrm{H}$ amination of quinolinamides and imidazopyridines

2018 年, 魏伟课题组 ${ }^{[83]}$ 报道了 $\mathrm{C}\left(\mathrm{sp}^{2}\right)-\mathrm{H}$ 键和 $\mathrm{N}-$ $\mathrm{H}$ 键之间的交叉脱氢偶联反应. 在蓝光的照射下，以 Eosin Y 染料作光敏剂, 在四氢呋喃溶液中, 室温条件 下通过自由基介导合成 3-氨基喹喔啉-2(1H)-酮(Eq. 55). 该方法操作简单，反应条件温和，具有较好的原子经济 性.

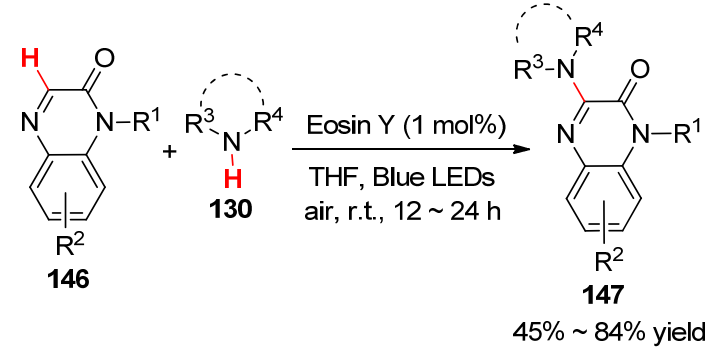

2018 年, 何延红课题组 ${ }^{[84]}$ 报道了唑类和缺电子烯 烃的光催化交叉脱氢偶联. 在光照条件下, 以 Rose Bengal 染料作光敏剂, 丙酮溶液中室温反应 $24 \mathrm{~h}$ 实现了 $\mathrm{C}\left(\mathrm{sp}^{2}\right)-\mathrm{H}$ 的胺化反应( Eq. 56). 该合成方法操作简便， 反应条件温和，具有优异的官能团耐受性和区域选择 性，为 $N$-乙烯基吡唑的合成提供了一种新方法.

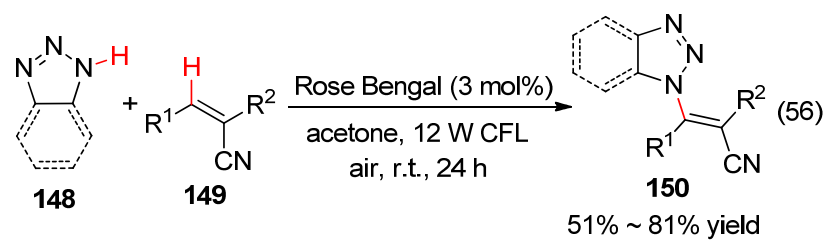

\section{$3 \mathrm{C}$ - $\mathrm{O}$ 偶联反应}

2013 年, Pandey 课题组 ${ }^{[85]}$ 报道了分子内芐基 $\mathrm{C}\left(\mathrm{sp}^{3}\right)-\mathrm{H}$ 官能化的环醚化反应. 反应以 $1,4-$ 二氧基菜 $(\mathrm{DCN})$ 为催化剂, 在光照及室温条件下, 于乙腈溶剂中 
进行(Eq. 57). 通过光诱导电子转移生成的自由基阳离 子进行催化反应. 该催化体系具有优异的区域选择性, 产物产率良好。

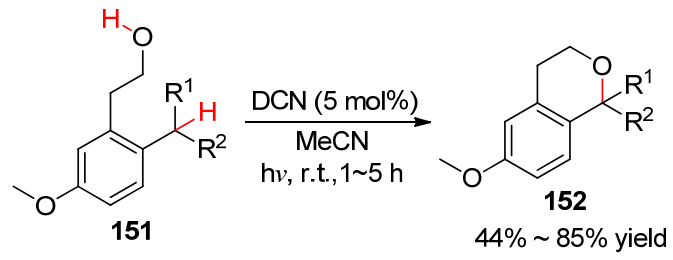

2014 年, 吴骊珠课题组 ${ }^{[86]}$ 报道了在蓝光的照射下, 以 TBA-Eosin Y 染料作光敏剂, 二氮杂二环 $(\mathrm{DBU})$ 作碱, 利用分子内交叉脱氢偶联合成 2-取代苯并噁唑的反应 (Eq. 58). 反应过程中, 在 TBA-Eosin Y 染料的作用下, 底物转化成自由基中间体, 再进一步进行光催化脱氢得 到产物, 其中添加碱有助于电子转移, 抑制单线态氧的 副反应. 该反应为分子内 $\mathrm{C}-\mathrm{O}$ 键的构建开辟了有效途 径.

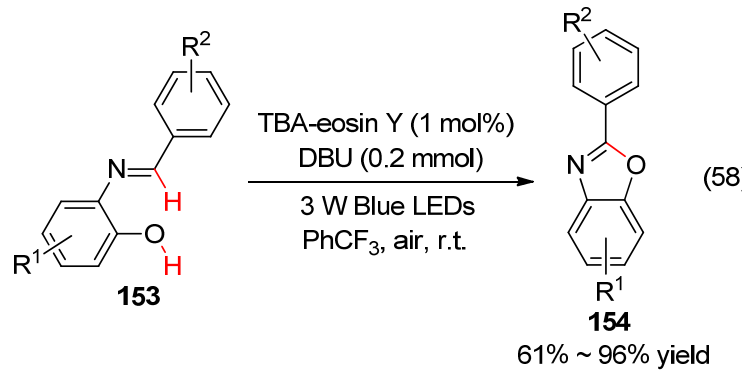

2015 年, Gonzalez-Gomez 等 ${ }^{[87]}$ 采用鲐啶染料作为 光催化剂, 在室温下实现了2-芳基苯甲酸的分子内脱氢 酯化. 该反应在可见光照射下，首次利用 $\left[\mathrm{Acr}{ }^{+}\right.$ -Mes-Me] $\left[\mathrm{ClO}_{4}{ }^{-}\right]$和 $\left(\mathrm{NH}_{4}\right)_{2} \mathrm{~S}_{2} \mathrm{O}_{8}$ 的催化组合制备了 3,4-苯 并香豆素(Eq. 59). 反应通过均裂芳香取代机理进行, 具 有操作简便和条件温和等优点. 随后, 雷爱文课题组 ${ }^{[88]}$ 同样以 $\left[\mathrm{Acr}^{+}-\mathrm{Mes}\right]\left[\mathrm{ClO}_{4}{ }^{-}\right]$作为光催化剂, 在助催化剂 TEMPO 的作用下, 得到了烯烃阳离子自由基, 在氮气 保护下实现了烯烃与醇的交叉脱氢偶联(Eq. 60).
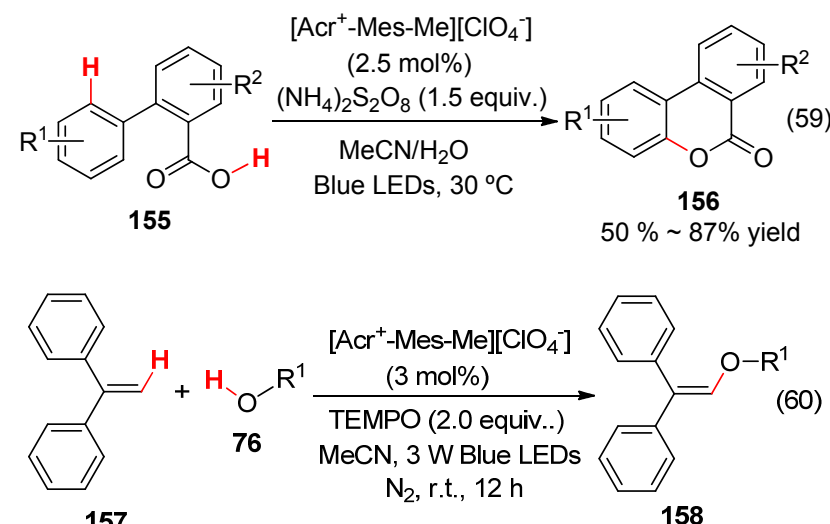

157

$55 \% \sim 77 \%$ yield
2016 年, Gilmour 等 ${ }^{[89]}$ 以(一)-核黄素作为催化剂, 利用它的两种光化学活化模式, 分别通过能量转移和单 电子转移依次进行诱导异构化和环化途径合成香豆素 衍生物(Eq. 61), 其中最关键的步骤是 $E$ 构型到 $Z$ 构型的 转化. 该催化体系对芳环上的取代基都具有良好的耐受 性，是有机光化学方法的有益拓展.

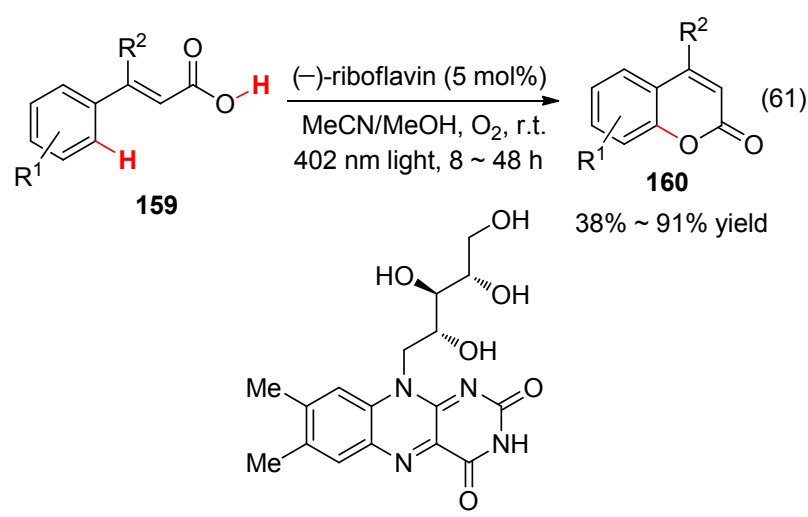

(-)-riboflavin

2017 年, Deb 等 ${ }^{[90]}$ 研究了自由基介导下 1-氨基烷 基-2-菜酚的分子内交叉脱氢偶联反应. 该反应以绿光 作为光源, Eosin Y 染料为光敏剂, 在乙腈溶液中以中等 收率得到产物啞嗪(Eq. 62). 该方法无需过渡金属催化 剂以及其他添加剂, 绿色环保.
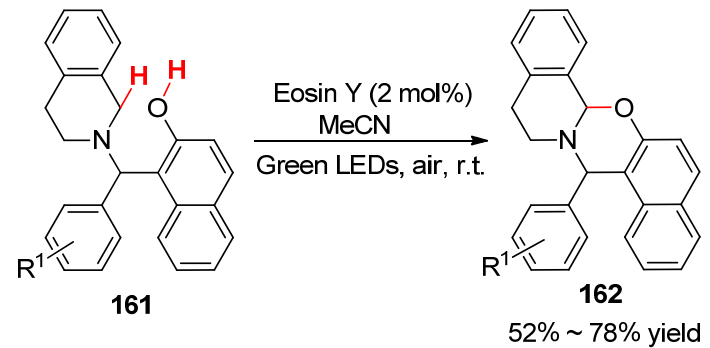

(62)

2017 年, Hajra 课题组 ${ }^{[91]}$ 报道了可见光介导的咪唑 并吡啶 C-3 烷氧基化反应. 以醇作氧源，在 Rose Bengal 染料的催化下，室温下进行反应，以良好的产率得到了 $\mathrm{C}\left(\mathrm{sp}^{2}\right)-\mathrm{H}$ 烷氧基化产物(Eq. 63). 该方法具有官能团耐 受性好, 反应条件温和等优点.

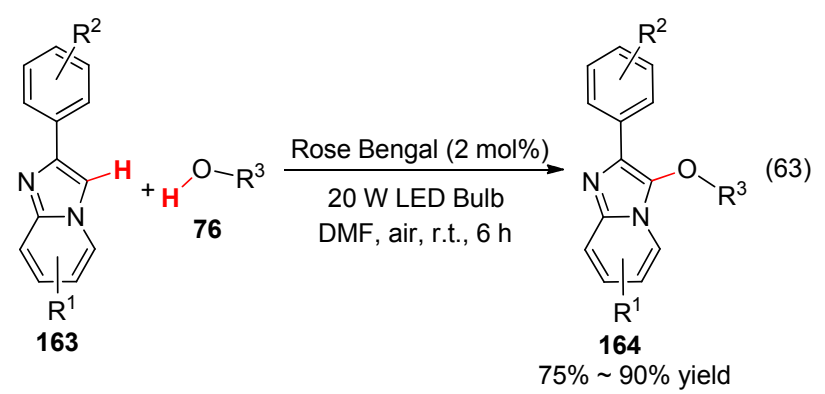




\section{$4 \mathrm{C}$-P 偶联反应}

2011 年, König 等 ${ }^{[35]}$ 在研究了 Eosin Y 染料催化下 $N$-芳基四氢异喹啉和亲核试剂两者间的 $\mathrm{C}\left(\mathrm{sp}^{3}\right)-\mathrm{C}\left(\mathrm{sp}^{3}\right)$ 键偶联后, 将亲核试剂扩展到二烷基磷酸酯继续进行研 究, 得到了高产率的产物(Eq. 64). 2015 年, 吴骊珠等 ${ }^{[41]}$ 以 BODIPY 染料为光敏剂, 也将亲核试剂扩展到二烷基 磷酸酯(Eq. 65). 与以往构建 $\mathrm{C}\left(\mathrm{sp}^{3}\right)$ - $\mathrm{P}$ 键需要金属催化 剂和昂贵的氧化剂不同, 这两种催化体系具有条件温 和、操作简便及反应时间短等优点, 为 $\mathrm{C}\left(\mathrm{sp}^{3}\right)-\mathrm{P}$ 键的 构建提供了新方法.
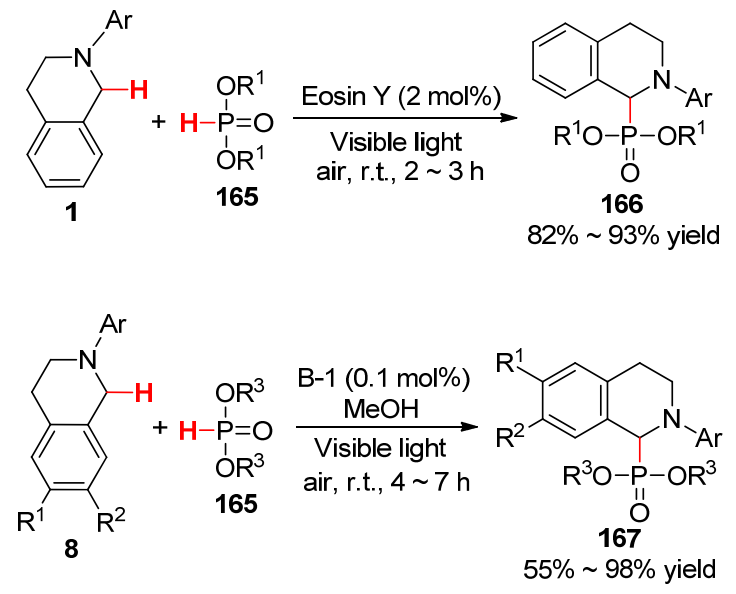

(65)

2016 年, 吴否课题组 ${ }^{[92]}$ 首次报道了无金属催化条 件下的光催化 $\mathrm{C}\left(\mathrm{sp}^{2}\right)-\mathrm{P}$ 成键交叉脱氢偶联反应. 利用 有机小分子染料 Eosin B 作为光敏剂, 在可见光的照射 下反应 $24 \mathrm{~h}$, 利用苯并噻唑和芳基磷氧化合物之间的交 叉脱氢偶联实现了 $\mathrm{C}-\mathrm{H}$ 的直接磷酰化 (Eq. 66). 该过程 通过二苯基膦自由基与苯并噻唑亲核加成, 然后去质子 化得到产物. 该方法在温和的室温条件下即可高效构建 $\mathrm{C}-\mathrm{P}$ 键, 氢气为唯一副产物, 无需氧化剂和任何添加 剂, 且对各种官能团都具有很好的耐受性. 同年, 雷爱 文课题组 ${ }^{[93]}$ 利用 $\mathrm{Na}_{2}$-Eosin $\mathrm{Y}$ 染料作为光敏剂, 实现了 $\mathrm{C}\left(\mathrm{sp}^{2}\right)-\mathrm{P}$ 键的形成(Eq. 67). 该合成方法既降低了催化 剂用量, 又缩短了反应时间.

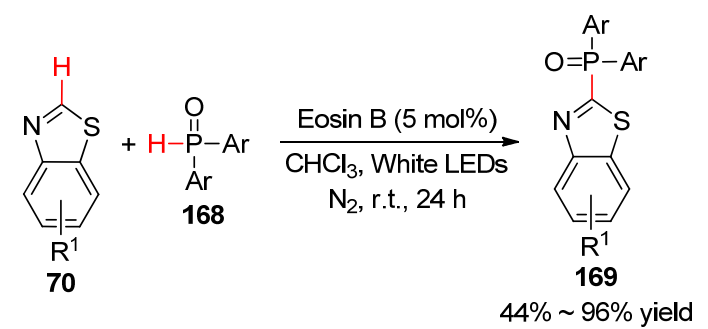

2017 年，吴养洁等 ${ }^{[94]}$ 报道了在绿光的照射下，以 Eosin $\mathrm{Y}$ 染料为光敏剂, 过氧化二苯甲酰(BPO)为氧化

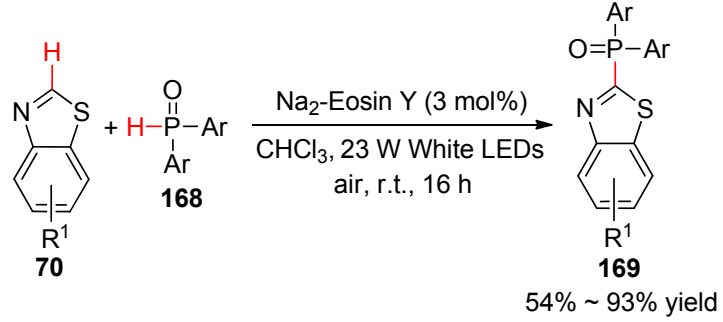

剂, 在氩气的保护下, 乙腈溶剂中反应 $24 \mathrm{~h}$, 实现了香 豆素衍生物的 C-3 位膦酰化(Eq. 68). 通过对照实验证明 活性中间体以 $\mathrm{P}$ 为中心的自由基在反应过程中起到关键 作用. 该催化体系对于多取代的香豆素具有广泛的适用 性, 且产率优良, 但反应需在氩气保护下进行且反应时 间较长.
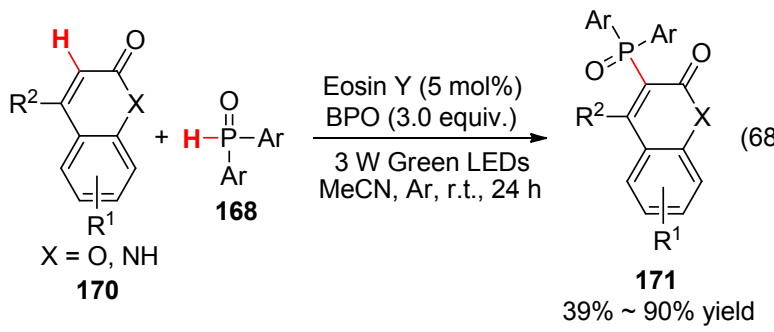

2018 年, Hajra 课题组 ${ }^{[95]}$ 报道了在室温和光照条件 下, 以 Rose Bengal 染料作光敏剂, 二氮杂二环(DBU)作 碱，在乙腈和水溶剂中反应 $16 \mathrm{~h}$, 实现了 $2 \mathrm{H}$-吲唑的 $\mathrm{C}\left(\mathrm{sp}^{2}\right)-\mathrm{H}$ 膦酰化反应(Eq. 69), 产率良好. 该过程为合 成含磷的芳香族化合物提供了一种有效的方法.

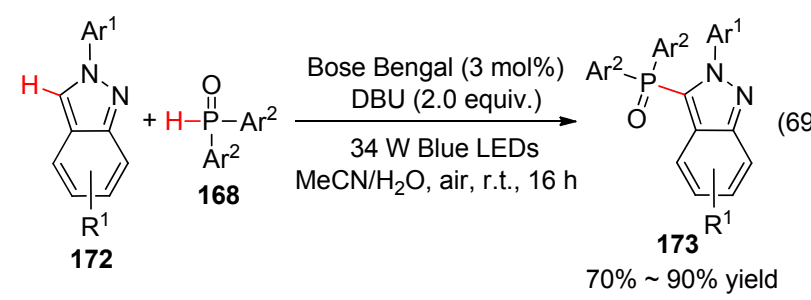

\section{5 成环反应}

2015 年, Brasholz 课题组 ${ }^{[96]}$ 报道了在可见光的照射 下，以 1-(硝基甲基)-2-芳基四氢异喹啉为底物，1-氨基 葱醌(1-AAQ)作光催化剂, $\mathrm{K}_{3} \mathrm{PO}_{4}$ 作碱, 室温下在乙腈溶 剂中通过交叉脱氢-环化合成 12-硝基取代的四环吲哚 [2,1- $\alpha]$ 异喹啉衍生物(Eq. 70). 目标产物也可直接通过 $N$-芳基四氢异喹啉和硝基甲烷在该催化体系下一锅法 进行四重级联转化获得. 该研究证明了葱醌衍生物的高 效催化能力, 反应过程中需要碱的参与, 且部分化合物 反应时间长达 $140 \mathrm{~h}$ ，尚待进一步改进.

2018 年, 江智勇课题组 ${ }^{[97]}$ 制备了 9 种二氧基吡嗪类 
<smiles>[R]c1cccc(N2CCc3ccccc3C2(CC)[C@H]([Y6])[N+](=O)[O-])c1</smiles><smiles>[R]c1ccc2c([N+](=O)[O-])c3n(c2c1)CCc1ccccc1-3</smiles>

$30 \% \sim 69 \%$ yield

光敏分子(DPZ)和二氧基咪唑衍生物(DCI)作为光催化 剂, 在蓝光的照射下, 二氯甲烷溶剂中, 于 $25{ }^{\circ} \mathrm{C}$ 反应 6 $\mathrm{h}$ 实现了 $N$-芳基四氢异喹啉和顺丁烯二酰亚胺的环化反 应(Eq. 71). 实验证明 DPZ 比 DCI 更高效. 此催化体系 具有条件温和、操作简便和催化效果好等优点, 符合绿 色化学的要求.

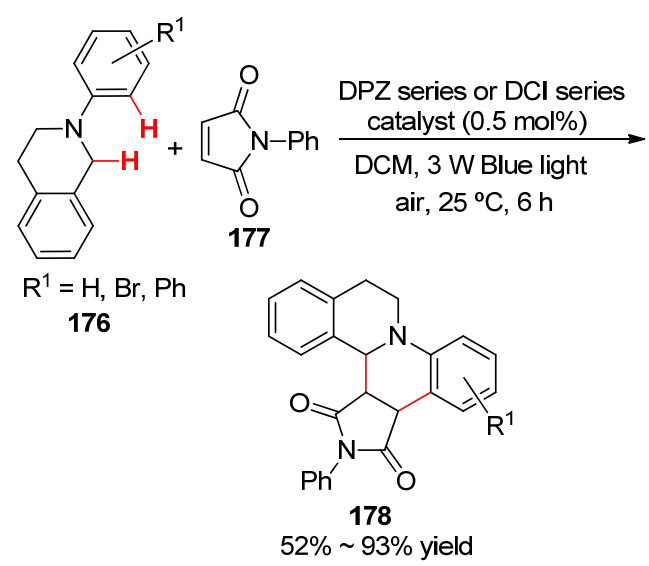

2018 年, 张元课题组 ${ }^{[98]}$ 研究了基于交叉脱氢偶联 的环化串联反应. 以蓝光为光源, 在光敏剂 Eosin $Y$ 染 料的催化下, 甘氨酸酯与 2,3-二氢呋喃在室温下进行交 叉脱氢偶联生成关键中间体 $179 \mathrm{a}$, 随后该中间体经过 酸化、酯交换和芳构化获得一系列喹啉稠合内酯化合物 (Scheme 16). 该方法是实现仲胺 $\alpha-\mathrm{C}-\mathrm{H}$ 官能化的一条 有效途径.

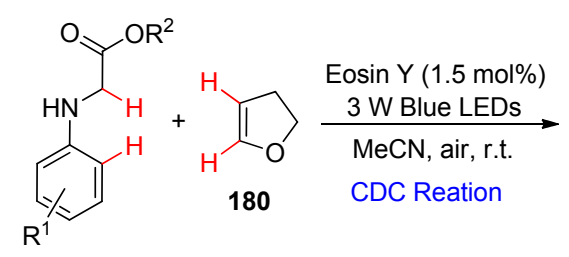

179

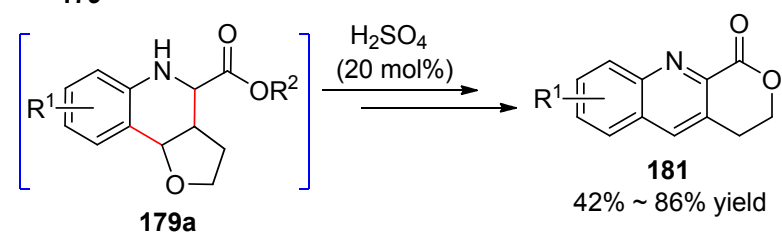

图式 16 甘氨酸酯与 2,3-二氢呋喃的交叉脱氢环化反应 Scheme 16 Cross dehydrocyclization reaction of glycine esters with 2,3-dihydrofuran

随后，该课题组 ${ }^{[99]}$ 在 $\mathrm{Rh}-6 \mathrm{G}$ 染料和硫酸的催化体系

中实现了甘氨酸酯与 $\alpha$-当归内酯的交叉脱氢-环化反应 (Scheme 17). 首先甘氨酸酯与 $\alpha$-当归内酯发生 $\mathrm{C}\left(\mathrm{sp}^{3}\right)$ $\mathrm{C}\left(\mathrm{sp}^{2}\right)$ 偶联反应生成中间体 $\mathbf{1 7 9 b}$ ，随后经过分子内亲核 取代和去质子化得到目标产物 183. 该反应条件温和, 合成的 $\gamma$-内酰胺可作为重要中间体合成复杂天然产物.
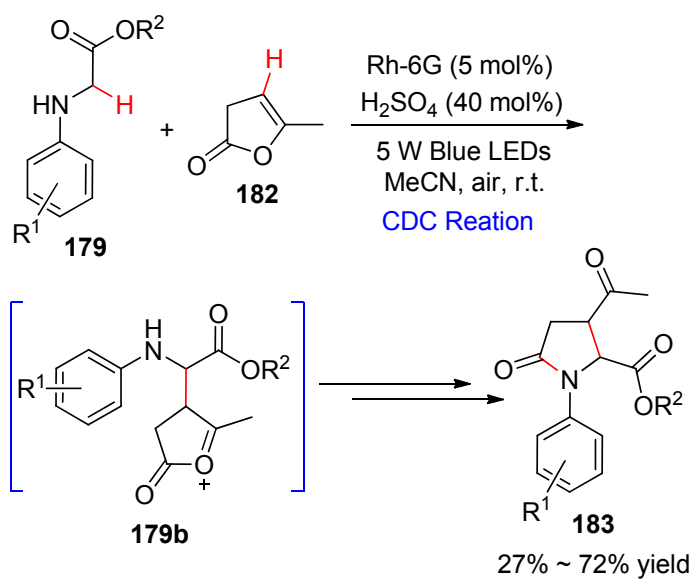

图式 17 甘氨酸酯与 $\alpha$-当归内酯的交叉脱氢环化反应 Scheme 17 Cross dehydrocyclization reaction of glycine esters with $\alpha$-angelica lactone

2018 年, Chuah 课题组 ${ }^{[100]}$ 报道了 1,3-二羰基化合物 和硫脲的偶联反应，在绿光的照射下，以四碘荧光素染 料作光催化剂, 合成了氨基噻唑(Scheme 18). 该过程中 硫脲首先生成硫自由基，随后与二羰基化合物的烯醇式 互变异构体结合生成中间体 184a，随后发生分子内环 化反应得到目标产物 186.
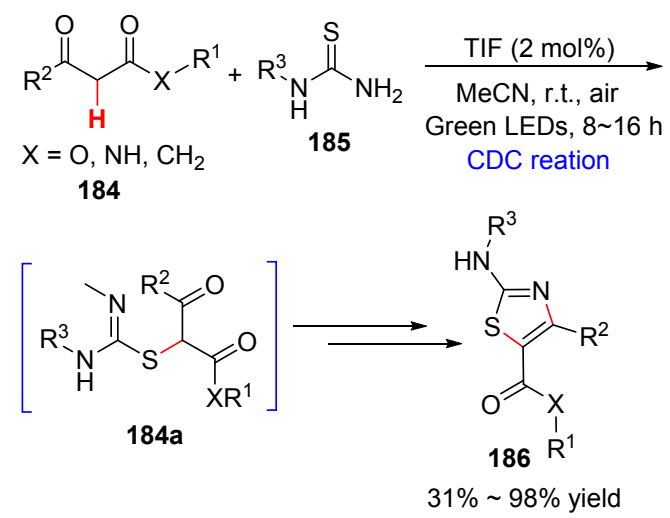

图式 18 二羰基化合物和硫艮的偶联环化反应 Scheme 18 Coupling-cyclization reaction of dicarbonyl compounds with thioureas

\section{6 其他偶联反应 $(C-S i, N-P, S-S, S-P)$}

2015 年, Noël 课题组 ${ }^{[101]}$ 报道了在光催化条件下硫 酚通过分子间脱氢偶联生成二硫化物的反应. 在 $24 \mathrm{~W}$ 紧凑型苂光灯照射下，以 Eosin Y 染料作光敏剂，乙醇 溶剂中反应 $16 \mathrm{~h}$, 通过一锅法高产率地合成了二硫化 
物. 随后又运用了连续流反应方法, 加入添加剂四甲基 乙二胺(TMEDA)进行反应, 仅需 $20 \mathrm{~min}$ 便得到高产率 二硫化物(Scheme 19). 与传统硫醇氧化法相比较, 该催 化体系避免了金属催化剂和氧化物的参与, 绿色环保, 提高了原子经济性.

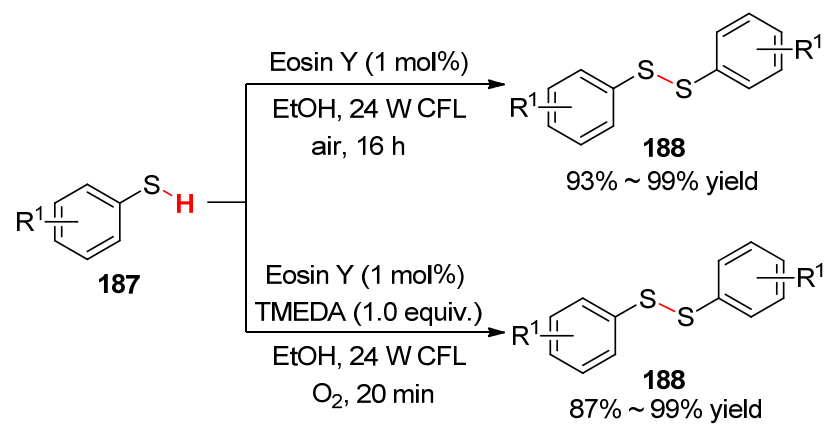

图式 19 分子间脱氢偶联合成二硫化物

Scheme 19 Synthesis of disulfides by intermolecular dehydrocoupling reaction

2016 年, Wacharasindhu 课题组 ${ }^{[102]}$ 报道了在可见光 的照射下, 以 Rose Bengal 染料为光敏剂, 于室温下水 溶剂中实现硫醇合成二硫化物的反应(Eq. 72). 该催化 体系条件温和, 无需金属催化或氧化剂参与, 产物产率 较高.

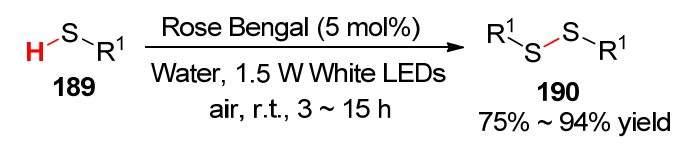

2016 年, 李萍课题组 ${ }^{[103]}$ 报道了在蓝光的照射下, 以 Rose Bengal 染料作光敏剂, 在室温下实现了硫醇和 有机磷化合物的交叉偶联反应(Eq. 73). 推测其反应机 理如下: 首先, $\mathrm{RB}$ 在光照下被激发成激发态 $\mathrm{RB}^{*}$, 其与 $\mathrm{O}_{2}$ 通过能量转移生成单线态氧 $\left({ }^{1} \mathrm{O}_{2}\right)$, 同时激发态 $\mathrm{RB}^{*}$ 返回其基态 $\mathrm{RB}$. 随后, ${ }^{1} \mathrm{O}_{2}$ 从硫醇 189 中夺取氢原子得 到硫基自由基 189a, 其快速偶联形成二硫化物 190. 另 一方面, ${ }^{1} \mathrm{O}_{2}$ 与烷基膦氧化物 191 发生氢原子转移生成以 $\mathrm{P}$ 为中心基团的自由基 191a. 最后, 191a 与硫基自由基 189a 偶联(Path A), 或者 191a 与二硫化物 190 偶联(Path $\mathrm{B})$, 或者可以通过 $191 \mathrm{~b}$ 亲核进攻二硫化物 190 产生目标 产物 192 (Path C)(Scheme 20). 该方法避免了过渡金属 催化剂的使用, 也无需高温条件, 是一条绿色的合成路 径.

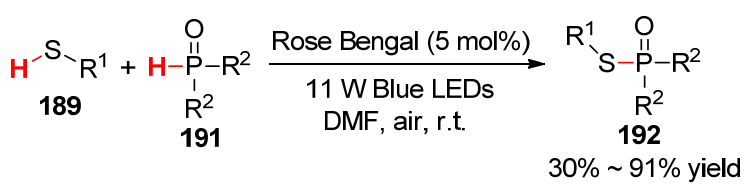

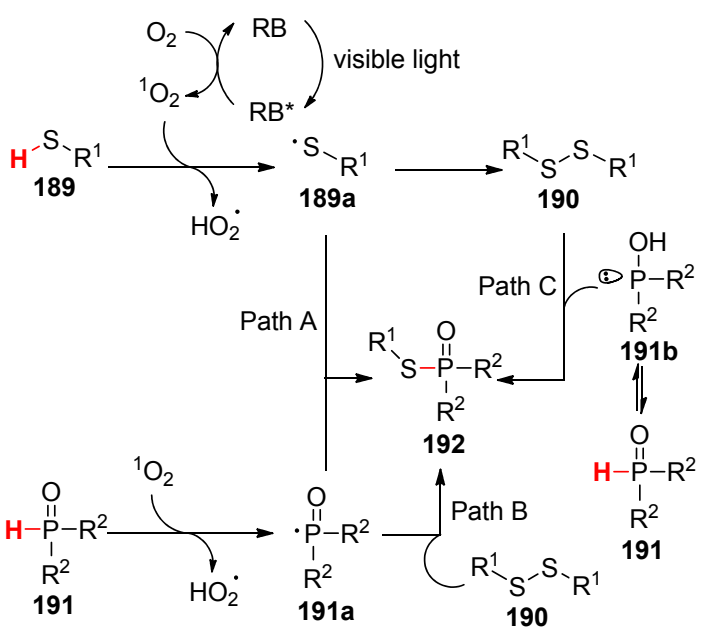

图式 20 硫醇和有机磷化合物的交叉脱氢偶联反应机理 Scheme 20 Cross dehydrogenation coupling reaction mechanism of mercaptan and organophosphorus compounds

2016 年, Rios 课题组 ${ }^{[104]}$ 首次使用有机染料在光催 化条件下合成氨基磷酸酯. 在绿光的照射下, 以 Rose Bengal 染料作光敏剂, 亚磷酸二乙酯作磷源, 在 $70{ }^{\circ} \mathrm{C}$ 下反应实现了芳香胺和脂肪族胺的磷酸化(Eqs. 74, 75). 该合成反应通过一锅法进行, 是一个体系温和、绿色高 效的过程, 为 $\mathrm{N}-\mathrm{P}$ 键的构建提供了一条简单易行的途 径.

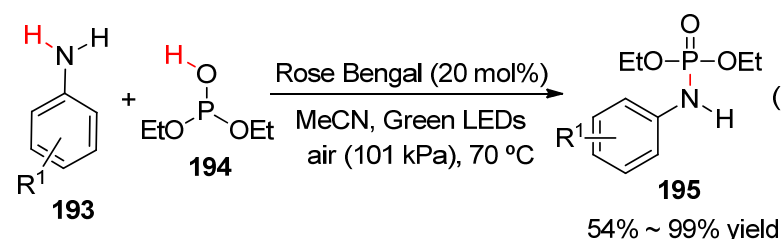

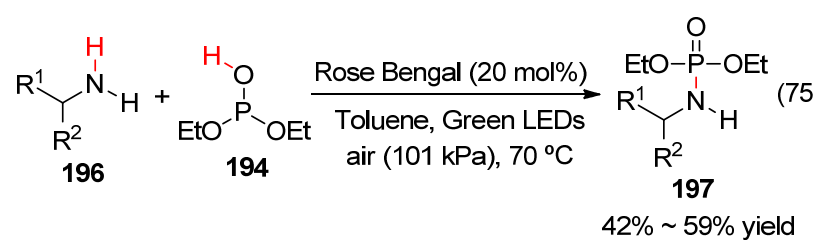

2018 年，吴勇等 ${ }^{[105]}$ 利用亚甲基蓝作光敏剂, $\mathrm{K}_{2} \mathrm{CO}_{3}$ 作碱, 异丙醇作溶剂, 在蓝光、室温和空气条件下合成 了硫代磷酸酯(Eq. 76). 该合成方法具有底物范围广，官 能团耐受性高的特点, 适用于含氨基、羟基、氰基和三 氟甲基等基团的衍生物.

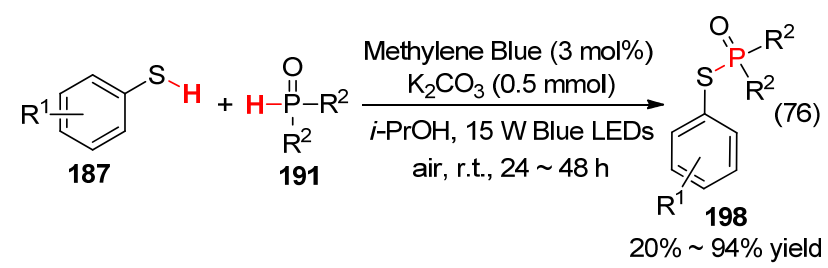

2018 年, 姜超课题组 ${ }^{[106]}$ 报道了二芳基硅烷通过分 
子内交叉脱氢偶联合成具有特殊有机电致发光特性的 二苯并噻咯(硅芴)的反应. 该反应以 Rose Bengal 染料作 光敏剂, TBHP 作氧化剂, $\mathrm{KOH}$ 作碱, 在温和的条件下实 现了 $\mathrm{C}-\mathrm{Si}$ 键的形成(Eq. 77). 该方法可广泛用于硅芴衍 生物的合成，以拓展其在光电材料领域中的应用.

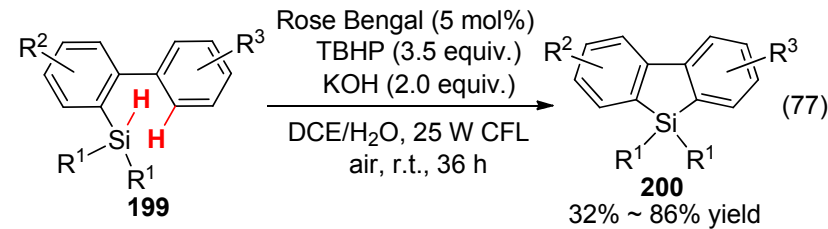

\section{7 结论与展望}

列举了可见光诱导的无过渡金属催化的交叉脱氢 偶联反应，其中包括 $\mathrm{C}-\mathrm{C}, \mathrm{C}-\mathrm{N}, \mathrm{C}-\mathrm{O}, \mathrm{C}-\mathrm{P}, \mathrm{C}-\mathrm{Si}$, $\mathrm{S}-\mathrm{S}, \mathrm{S}-\mathrm{P}, \mathrm{N}-\mathrm{P}$ 键偶联和成环的反应实例. 在上述光 诱导的交叉脱氢偶联反应中, 通常以氧杂蒽类染料(如 Rose Bengal 和 Eosin Y)、蒽醌类染料(如 AAQ 和 AQN)、 呋啶类染料、BODIPY 染料、吩嗪类化合物、吡嗪类化 合物、固体催化剂(如 $m p g-\mathrm{C}_{3} \mathrm{~N}_{4}$ ) 及负载型催化剂(如 PDMS-RB 和 Cot-RB)等作为光催化剂, 避免了过渡金 属的参与, 具有绿色环保、温和高效以及原子经济性高 的优点. 目前, 根据一些研究报道 ${ }^{[107 ~ 109]}$, 光催化剂和 质子还原助催化剂结合形成的新型双催化体系可增强 光吸收效率, 其利用光催化剂引发电子转移, 质子还原 催化剂捕获电子，显著提高了光催化产氢的活性. 但是 上述质子还原催化剂由于含有过渡金属, 通常能耗大, 污染严重且价格昂贵. 因此, 可以进一步研究环境友好 的非金属光协同催化剂, 用以开发更绿色、高效和广泛 的交叉脱氢偶联反应.

综上所述，可见光诱导的无过渡金属催化交叉脱氢 偶联反应已成为有机合成领域新的研究方向和热点之 一, 值得进一步探索与研究.

\section{References}

[1] Girard, S. A.; Knauber, T.; Li, C. J. Angew. Chem., Int. Ed. 2014, $53,74$.

[2] Ji, D.-R.; Yang, H.; Zhao, X.-J.; Yang, H.; Liu, Y.-Z.; Liao, D.-H.; Feng, C.; Zhang, C.-G. Chin. Chem. Lett. 2014, 25, 348.

[3] Batra, A.; Singh, P.; Singh, K. N. Eur. J .Org. Chem. 2016, 2016, 4927.

[4] Batra, A.; Singh, P.; Singh, K. N. Eur. J .Org. Chem. 2017, 2017, 3739.

[5] Hosseinian, A.; Ahmadi, S.; Nasab, F. A. H.; Mohammadi, R.; Vessally, E. Top. Curr. Chem. 2018, 376, 39.

[6] Liu, C.; Yuan, J.; Gao, M.; Tang, S.; Li, W.; Shi, R.; Lei, A. Chem. Rev. 2015, 115, 12138

[7] Yi, H.; Zhang, G.; Wang, H.; Huang, Z.; Wang, J.; Singh, A. K.; Lei, A. Chem. Rev. 2017, 117, 9016.

[8] Tang, S.; Zeng, L.; Lei, A. J. Am. Chem. Soc. 2018, 140, 13128

[9] Boess, E.; Schmitz, C.; Klussmann, M. J. Am. Chem. Soc. 2012,
$134,5317$.

[10] Matcha, K.; Antonchick, A. P. Angew. Chem., Int. Ed. 2013, 52, 2082.

[11] Lv, L.; Li, Z. Top. Curr. Chem. 2016, 374, 1.

[12] Eisenhofer, A.; Hioe, J.; Gschwind, R. M.; König, B. Eur. J .Org. Chem. 2017, 2017, 2194

[13] Dong, J.; Xia, Q.; Lv, X.; Yang, C.; Song, H.; Liu, Y.; Wang, Q. Org. Lett. 2018, 20, 5661.

[14] Hu, X.; Zhang, G.; Bu, F.; Luo, X.; Yi, K.; Zhang, H.; Lei, A. Chem. Sci. 2018, 9, 1521 .

[15] Samanta, S.; Hajra, A. J. Org. Chem. 2019, 84, 4363.

[16] Antonchick, A.; Murarka, S. Synthesis 2018, 50, 2150.

[17] Faisca Phillips, A. M.; Pombeiro, A. J. L. ChemCatChem 2018, 10 , 3354.

[18] Prendergast, A. M.; McGlacken, G. P. Eur. J. Org. Chem. 2018, $2018,6068$.

[19] Narayan, R.; Matcha, K.; Antonchick, A. P. Chemistry 2015, 21, 14678.

[20] Wang, B.; Wong, H. N. C. Bull. Chem. Soc. Jpn. 2018, 91, 710.

[21] Parvatkar, P. T.; Manetsch, R.; Banik, B. K. Chem.-Asian J. 2019, 14,6 .

[22] Narayanam, J. M.; Stephenson, C. R. Chem. Soc. Rev. 2011, 40, 102.

[23] Shi, L.; Xia, W. Chem. Soc. Rev. 2012, 41, 7687.

[24] Tucker, J. W.; Stephenson, C. R. J. Org. Chem. 2012, 77, 1617.

[25] Xuan, J.; Xiao, W.-J. Angew. Chem., Int. Ed. 2012, 51, 6828.

[26] Prier, C. K.; Rankic, D. A.; MacMillan, D. W. Chem. Rev. 2013, 113,5322

[27] Romero, N. A.; Nicewicz, D. A. Chem. Rev. 2016, 116, 10075

[28] Wei, G.; Basheer, C.; Tan, C.-H.; Jiang, Z. Tetrahedron Lett. 2016 , $57,3801$.

[29] Dai, X.-Q.; Zhu, Y.-B.; Xu, X.-L.; Weng, J.-Q. Chin. J. Org. Chem. 2017, 37, 577 (in Chinese). (戴小强, 朱亚波, 许孝良, 翁建全, 有机化学, 2017, 37, 577.)

[30] Xu, W.-X.; Dai, X.-Q.; Xu, H.-J.; Weng, J.-Q. Chin. J. Org. Chem. 2018, 38, 2807 (in Chinese). (徐雯秀，戴小强，徐涵靖，翁建全，有机化学, 2018, 38, 2807.)

[31] Chen, B.; Wu, L.-Z.; Tung, C.-H. Acc. Chem. Res. 2018, 51, 2512.

[32] Zhang, H.; Lei, A. Asian J. Org. Chem. 2018, 7, 1164

[33] Lei, A.; Zhang, H. Synthesis 2018, 51, 83.

[34] Pan, Y.; Kee, C.-W.; Chen, L.; Tan, C.-H. Green Chem. 2011, 13 , 2682.

[35] Hari, D. P.; König, B. Org. Lett. 2011, 13, 3852

[36] Liu, Q.; Li, Y.-N.; Zhang, H.-H.; Chen, B.; Tung, C.-H.; Wu, L.-Z. Chem.-Eur. J. 2012, 18, 620 .

[37] Möhlmann, L.; Baar, M.; Rieß, J.; Antonietti, M.; Wang, X.; Blechert, S. Adv. Synth. Catal. 2012, 354, 1909.

[38] Rueping, M.; Vila, C.; Bootwicha, T. ACS Catal. 2013, 3, 1676

[39] Zhao, Y.; Zhang, C.; Chin, K. F.; Pytela, O.; Wei, G.; Liu, H.-J.; Bureš, F.; Jiang, Z.-Y. RSC Adv. 2014, 4, 30062.

[40] Itoh, A.; Yamaguchi, T.; Nobuta, T.; Tada, N.; Miura, T.; Nakayama, T.; Uno, B. Synlett 2014, 25, 1453.

[41] Wang, X.-Z.; Meng, Q.-Y.; Zhong, J.-J.; Gao, X.-W.; Lei, T.; Zhao, L.-M.; Li, Z.-J.; Chen, B.; Tung, C.-H.; Wu, L.-Z. Chem. Commun. $\mathbf{2 0 1 5}, 51,11256$

[42] Gandy, M. N.; Raston, C. L.; Stubbs, K. A. Chem. Commun. 2015 , $51,11041$.

[43] Franz, J. F.; Kraus, W. B.; Zeitler, K. Chem. Commun. 2015, 51, 8280.

[44] Shirley, L. D.; Ceban, V.; Meazza, M.; Rios, R. Chem. Sci. 2016, 1, 13.

[45] Li, X.; Li, Y.; Huang, Y.; Zhang, T.; Liu, Y.; Yang, B.; He, C.; Zhou, X.; Zhang, J. Green Chem. 2017, 19, 2925.

[46] Zhang, T.; Liang, W.; Huang, Y.; Li, X.; Liu, Y.; Yang, B.; He, C.; Zhou, X.; Zhang, J. Chem. Commun. 2017, 53, 12536.

[47] Xiao, L.; Huang, Y.; Luo, Y.; Yang, B.; Liu, Y.; Zhou, X.; Zhang, J. ACS Sustainable Chem. Eng. 2018, 6, 14759.

[48] Liu, W.; Su, Q.; Ju, P.; Guo, B.; Zhou, H.; Li, G.; Wu, Q. 
ChemSusChem 2017, 10, 664.

[49] Liu, W.; Wu, S.; Su, Q.; Guo, B.; Ju, P.; Li, G.; Wu, Q. J. Mater. Sci. 2018, 54, 1205.

[50] Chen, K.; Cheng, Y.; Chang, Y.; Li, E.; Xu, Q.-L.; Zhang, C.; Wen, X.; Sun, H. Tetrahedron 2018, 74, 483.

[51] Yang, J.; Xie, D.; Zhou, H.; Chen, S.; Duan, J.; Huo, C.; Li, Z. Adv. Synth. Catal. 2018, 360, 3471.

[52] Xiao, T.; Li, L.; Lin, G.; Mao, Z. W.; Zhou, L. Org. Lett. 2014, 16, 4232.

[53] Devari, S.; Shah, B. A. Chem. Commun. 2016, 52, 1490.

[54] Wei, G.; Zhang, C.; Bureš, F.; Ye, X.; Tan, C.-H.; Jiang, Z. ACS Catal. 2016, 6, 3708.

[55] Sudo, Y.; Yamaguchi, E.; Itoh, A. Org. Lett. 2017, 19, 1610.

[56] Wei, W.; Wang, L.; Yue, H.; Bao, P.; Liu, W.; Hu, C.; Yang, D.; Wang, H. ACS Sustainable Chem. Eng. 2018, 6, 17252.

[57] Kibriya, G.; Bagdi, A. K.; Hajra, A. J. Org. Chem. 2018, 83, 10619.

[58] Singsardar, M.; Laru, S.; Mondal, S.; Hajra, A. J. Org. Chem. 2019, 84,4543 .

[59] Sun, B.; Deng, J.; Li, D.; Jin, C.; Su, W. Tetrahedron Lett. 2018, 59, 4364.

[60] Zhang, Y.; Yang, X.; Zhou, H.; Li, S.; Zhu, Y.; Li, Y. Org. Chem. Front. 2018, 5, 2120.

[61] Weng, J.-Q.; Xu, W.-X.; Dai, X.-Q.; Zhang, J.-H.; Liu, X.-H. Tetrahedron Lett. 2019, 60, 390.

[62] Zhang, Y.; Teuscher, K. B.; Ji, H. Chem. Sci. 2016, 7, 2111.

[63] Niu, L.; Liu, J.; Liang, X.-A.; Wang, S.; Lei, A. Nat. Commun. 2019, 10, 467

[64] Liang, X. A.; Niu, L.; Wang, S.; Liu, J.; Lei, A. Org. Lett. 2019, 21, 2441.

[65] Huang, C.-Y.; Li, J.; Liu, W.; Li, C.-J. Chem. Sci. 2019, 10, 5018.

[66] Zhang, L.; Zhang, G.; Li, Y.; Wang, S.; Lei, A. Chem. Commun. 2018, 54,5744

[67] Xuan, J.; Feng, Z.-J.; Duan, S.-W.; Xiao, W.-J. RSC Adv. 2012, 2, 4065.

[68] Teo, Y. C.; Pan, Y.; Tan, C. H. ChemCatChem 2013, 5, 235.

[69] Leow, D. Org. Lett. 2014, 16, 5812.

[70] Pandey, G.; Laha, R. Angew. Chem., Int. Ed 2015, 54, 14875.

[71] Romero, N. A.; Margrey, K. A.; Tay, N. E.; Nicewicz, D. A. Science 2015, 349, 1326.

[72] Margrey, K. A.; Levens, A.; Nicewicz, D. A. Angew. Chem., Int. Ed. 2017, 56, 15644 .

[73] Meyer, A. U.; Berger, A. L.; Konig, B. Chem. Commun. 2016, 52, 10918.

[74] Sakakibara, Y.; Ito, E.; Kawakami, T.; Yamada, S.; Murakami, K.; Itami, K. Chem. Lett. 2017, 46, 1014.

[75] Song, C.; Yi, H.; Dou, B.; Li, Y.; Singh, A. K.; Lei, A. Chem. Commun. 2017, 53, 3689.

[76] Das, S.; Natarajan, P.; König, B. Chem.-Eur. J. 2017, 23, 18161.

[77] Martinez, C.; Bosnidou, A. E.; Allmendinger, S.; Muniz, K. Chemistry 2016, 22, 9929.

[78] Zhao, Y.-T.; Huang, B.-B.; Yang, C.; Xia, W.-J. Org. Lett. 2016, 18, 3326.

[79] Zhao, Y.-T.; Huang, B.-B.; Yang, C.; Li, B.; Gou, B.-Q.; Xia, W.-J. ACS Catal. 2017, 7, 2446.

[80] Yamaguchi, T.; Yamaguchi, E.; Itoh, A. Org. Lett. 2017, 19, 1282.
[81] Zhang, L.; Yi, H.; Wang, J.; Lei, A. J. Org. Chem. 2017, 82, 10704.

[82] Samanta, S.; Ravi, C.; Rao, S. N.; Joshi, A.; Adimurthy, S. Org. Biomol. Chem. 2017, 15, 9590 .

[83] Wei, W.; Wang, L.-L.; Bao, P.-L.; Shao, Y.; Yue, H.-Y.; Yang, D.-S.; Yang, X.-B.; Zhao, X.-H.; Wang, H. Org. Lett. 2018, 20, 7125.

[84] Xin, J.-R.; He, Y.-H.; Guan, Z. Org. Chem. Front. 2018, 5, 1684.

[85] Pandey, G.; Pal, S.; Laha, R. Angew. Chem., Int. Ed. 2013, 52, 5146.

[86] Wang, L.; Ma, Z.-G.; Wei, X.-J.; Meng, Q.-Y.; Yang, D.-T.; Du, S.-F.; Chen, Z.-F.; Wu, L.-Z.; Liu, Q. Green Chem. 2014, 16, 3752.

[87] Ramirez, N. P.; Bosque, I.; Gonzalez-Gomez, J. C. Org. Lett. 2015, 17,4550 .

[88] Yi, H.; Niu, L.; Song, C.; Li, Y.; Dou, B.; Singh, A. K.; Lei, A. Angew. Chem., Int. Ed. 2017, 56, 1120.

[89] Metternich, J. B.; Gilmour, R. J. Am. Chem. Soc. 2016, 138, 1040.

[90] [90] Borpatra, P. J.; Deb, M. L.; Baruah, P. K. Tetrahedron Lett. 2017, 58, 4006.

[91] Kibriya, G.; Samanta, S.; Jana, S.; Mondal, S.; Hajra, A. J. Org. Chem. 2017, 82, 13722.

[92] Luo, K.; Chen, Y. Z.; Yang, W. C.; Zhu, J.; Wu, L. Org. Lett. 2016, 18,452

[93] Peng, P.; Peng, L.; Wang, G.; Wang, F.; Luo, Y.; Lei, A. Org. Chem. Front. 2016, 3, 749 .

[94] Li, Q.-R.; Zhao, X.-L.; Li, Y.-B.; Huang, M.-M.; Kim, J. K.; Wu, Y.-J. Org. Biomol. Chem. 2017, 15, 9775.

[95] Singsardar, M.; Dey, A.; Sarkar, R.; Hajra, A. J. Org. Chem. 2018, 83, 12694.

[96] Rusch, F.; Unkel, L. N.; Alpers, D.; Hoffmann, F.; Brasholz, M. Chem.-Eur. J. 2015, 21, 8336.

[97] Hloušková, Z.; Tydlitát, J.; Kong, M.; Pytela, O.; Mikysek, T.; Klikar, M.; Almonasy, N.; Dvořák, M.; Jiang, Z.-Y.; Rűžička, A.; Bureš, F. ChemistrySelect 2018, 3, 4262.

[98] He, Y.; Yan, B.; Tao, H.; Zhang, Y.; Li, Y. Org. Biomol. Chem. 2018, 16, 3816.

[99] Zhou, H.; Yang, X.; Li, S.; Zhu, Y.; Li, Y.; Zhang, Y. Org. Biomol. Chem. 2018, 16, 6728.

[100] Roslan, I. I.; Ng, K.-H.; Gondal, M. A.; Basheer, C.; Dastageer, M. A.; Jaenicke, S.; Chuah, G.-K. Adv. Synth. Catal. 2018, 360, 1584.

[101] Talla, A.; Driessen, B.; Straathof, N. J. W.; Milroy, L.-G.; Brunsveld, L.; Hessel, V.; Noël, T. Adv. Synth. Catal. 2015, 357, 2180.

[102] Tankam, T.; Poochampa, K.; Vilaivan, T.; Sukwattanasinitt, M.; Wacharasindhu, S. Tetrahedron 2016, 72, 788.

[103] Sun, J.-G.; Yang, H.; Li, P.; Zhang, B. Org. Lett. 2016, 18, 5114.

[104] Meazza, M.; Kowalczuk, A.; Shirley, L.; Yang, J. W.; Guo, H.; Rios, R. Adv. Synth. Catal. 2016, 358, 719.

[105] Zhang, H.; Zhan, Z.; Lin, Y.; Shi, Y.-S.; Li, G.-B.; Wang, Q.-T.; Deng, Y.; Hai, L.; Wu, Y. Org. Chem. Front. 2018, 5, 1416.

[106] Yang, C.; Wang, J.; Li, J.-H.; Ma, W.-C.; An, K.; He, W.; Jiang, C. Adv. Synth. Catal. 2018, 360, 3049.

[107] Niu, L.; Yi, H.; Wang, S.; Liu, T.; Liu, J.; Lei, A. Nat. Commun. 2017, 8, 14226.

[108] Yang, Q.; Zhang, L.; Ye, C.; Luo, S.; Wu, L.-Z.; Tung, C.-H. Angew. Chem., Int. Ed. 2017, 56, 3694.

[109] Chen, H.; Yi, H.; Tang, Z.; Bian, C.; Zhang, H.; Lei, A. Adv. Synth. Catal. 2018, 360, 3220. 